\title{
4h. 2891
}

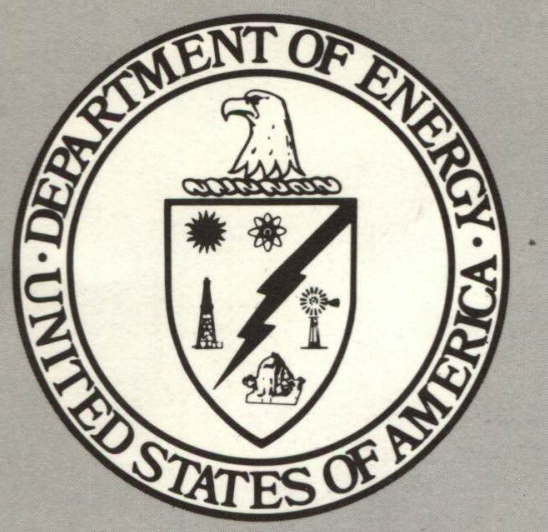

\section{MASTER}

COO-4057-9

GAS REACTOR INTERNATIONAL COOPERATIVE PROGRAM INTERIM REPORT

United States/Federal Republic of Germany Nuclear Licensing Comparison

September 1978

Work Performed Under Contract No. EN-77-C-02-4057

General Electric Company

Advanced Reactor Systems Department

Sunnyvale, California 


\section{DISCLAIMER}

This report was prepared as an account of work sponsored by an agency of the United States Government. Neither the United States Government nor any agency Thereof, nor any of their employees, makes any warranty, express or implied, or assumes any legal liability or responsibility for the accuracy, completeness, or usefulness of any information, apparatus, product, or process disclosed, or represents that its use would not infringe privately owned rights. Reference herein to any specific commercial product, process, or service by trade name, trademark, manufacturer, or otherwise does not necessarily constitute or imply its endorsement, recommendation, or favoring by the United States Government or any agency thereof. The views and opinions of authors expressed herein do not necessarily state or reflect those of the United States Government or any agency thereof. 


\section{DISCLAIMER}

Portions of this document may be illegible in electronic image products. Images are produced from the best available original document. 


\section{NOTICE}

This report was prepared as an account of work sponsored by the United States Government. Neither the United States nor the United States Department of Energy, nor any of their employees, nor any of their contractors, subcontractors, or their employees, makes any warranty, express or implied, or assumes any legal liability or responsibility for the accuracy, completeness or usefulness of any information, apparatus, product or process disclosed, or represents that its use would not infringe privately owned rights.

This report has been reproduced directly from the best available copy.

Available from the National Technical Information Service, U. S. Department of Commerce, Springfield, Virginia 22161.

Price: Paper Copy $\$ 6.00$

Microfiche $\$ 3.00$ 
CoO-4057-9

Distribution Category UC.77

\title{
GAS REACTOR INTERNATIONAL COOPERATIVE PROGRAM INTERIM REPORT
}

\author{
UNITED STATES/FEDERAL REPUBLIC OF GERMANY \\ NUCLEAR LICENSING COMPARISON
}

\author{
GENERAL ELECTRIC \\ ADVANCED REACTOR SYSTEMS DEPARTMENT \\ 310 DeGUIGNE DRIVE \\ SUNNYVALE, CALIFORNIA 94086
}

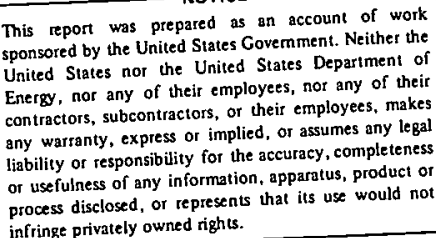

or usefulness of any information, apparatus, product or

process disclosed, or represents

Prepared for 


\section{$\underline{\text { ABSTRACT }}$}

In order to compare US and FRG Nuclear Licensing, a summary description of United States Nuclear Licensing is provided as a basis. This is followed by detailed information on the participants in the Nuclear Licensing process in the Federal Republic of Germany (FRG). FRG licensing procedures are described and the rules and regulations imposed are summarized. The status of gas reactor licensing in both the U.S. and the FRG is outlined and overall conclusions are drawn as to the major licensing differences. An appendix describes the most important technical differences between US and FRG criteria.

By agreement, this report has been reviewed by the cognizant Federal Republic of Germany industrial and laboratory operations and the resulting comments incorporated or noted herein. 
ABSTRACT

TABLE OF CONTENTS

LIST OF TABLES

LIST OF FIGURES

SECTION 1 - INTRODUCTION . . . . ............ . . $1-1$

1.1 Purpose . . . . . . . . . . . . . . . . . . . . 1-1

1.2 Background . . . . . . . . . . . . . . . . . . . 1-1

1.3 U.S. Nuclear Licensing . . . . . . ... . . . ... . 1-2

1.4 Report Summary. ...... . . . . . ........ . . 1-5

SECTION 2 - WEST GERMAN NUCLEAR LICENSING FRAMEWORK. . . . . . . 2-1

2.1 Background and General Discussion . . . . . . . . . 2-1

2.2. State Supreme Licensing Authorities... . . . . . . . 2-3

2.3 State Supervising Authorities . . . . . . . . . . . 2-6

2.4 Federal Ministry of the Interior (BMI) . . • . . . . . . . 2-6

2.5 The State Committee for Nuclear Energy (Landerausschuss). • . 2-9

2.6 Technical Inspection Agencies ( $\left.\mathrm{TUN}^{\prime} \mathrm{s}\right) . . . . . . . . . .2-10$

2.7 Confederation of Technical Inspection Agencies (VdTÜV). . . . 2-16

2.8 Company for Reactor Safety (GRS). . . . . . . . . . 2-16

2.9 Reactor Safety Commission (RSK) . . . . . . . . . . . 2-24

2.10 Radiation Protection Commission (SSK) . . . . . . . . 2-27

2.11 Nuclear Standards Commission (KTA). . . . . . . . . 2-27

SECTION 3 - LICENSING PROCEDURE IN THE FRG . . . . . . . . 3-1

3.1 Summary Description . . . . . . . . . . . . . . 3-1

3.2 First Partial-License Proceeding. . . . . . . . . . . 3-2

3.3 Supplemental Partial Licenses... . . . . . . . . 3-7

SECTION 4 - GENERAL DESCRIPTION OF GERMAN NUCLEAR CRITERIA • . . 4-1

4.1 Organization and Relationship . . . . . . . . . . . 4-1

4.2 The German Atomic Law . . . . . . . . . . . . . . 4-1 
4.3 Ordinances. . . . . . . . . . . . . . . . . . . . . . . . . 4-4

4.4 Safety Criteria for Nuclear Power Plants. . . . . . . . . . . 4-5

4.5 RSK Guidelines. . . . . . . . . . . . . . . . . . 4-7

4.6 Consensus Standards . . . . . . . . . . . . . . . . 4-7

4.7 Other Requirements. . . . . . . . . . . . . . . 4-8

SECTION 5 - GAS REACTOR LICENSING. . . . . . . . . . . . . . 5-1

5.1 Background. . . . . . . . . . . . . . . . . . . 5-1

5.2 Current Status. . . . . . . . . . . . . . . . 5-2

SECTION 6 - CONCLUSIONS. . . . . . . . . . . . . . . . . . 6-1

6.1 Procedural Differences. . . . . . . . . . . . . . 6-1

6.2 Technical Requirement Differences... . . . . . . . . 6-2

SECTION 7 - REFERENCES . . . . . . . . . . . . . . . . . 7-1

APPENDIX A - US/FRG TECHNICAL LICENSING CRITERIA . . . . . . . . . A-1

A.1 Introduction . . . . . . . . . . . . . . . . . . . A-1

A.2 Fundamental Differences. . . . . . . . . . . . . . A-2

A.3 Specific Differences in Criteria . . . . . . . . . . . . . A-17

A.4 Additional U.S. Requirements . . . . . . . . . . . . . . A-26

\section{LIST OF TABLES}

\section{$\underline{\text { Table }}$}

A-1 USNRC Branch Technical Positions . . . . . . . . . . . . . A-4

A-2 Summary of DIN Nuclear Standards . . . . . . . . . . . . A-8

A-3 ANSI Nuclear Standards Utilized in Reactor Design. . . . . . . A-10 


\section{LIST OF FIGURES}

Figure No.

'Page

1-1 U.S. Nuclear Regulatory Commission . . . . . . . 1-3

1-2 U.S. Construction Permit Review Process. ... . . . . . 1-4

2-1 Simplified FRG Licensing Flow Sheet. . . . . . . 2-4

2-2 Federal Ministry of the Interior (BMI). . . . . . 2-7

2-3 Typical TüV Organization . . . . . . . . . . 2-12

2-4 Typical TüV Nuclear Technology Department. . . . . 2-13

2-5 GRS Organization ............. . . 2-18

2-6. GRS Perspective of the Licensing Process . . . . . . 2-22

2-7. . GRS Expert Evaluations . . .......... . 2-23

2-8 RSK Perspective of the Licensing Process . . . . . 2-28

2-9 Organization of the KTA Secretariat. . . . . . . 2-30

2-10 Flow Scheme for the Preparation of KTA Standards . : 2-32

3-1 Partial License Procedure. . . . . . . . . . 3-3

3-2 Overall Licensing Schedule............ . 3-8

4-1 German Regulations and Guidelines. . . . . . . . 4-2 
SECTION 1

INTRODUCTION

\section{$1.1 \quad$ PURPOSE}

The International Gas Reactor Program contract between the General Electric Company (GE) and the U.S. Department of Energy (DOE) requires that GE provide guidance on possible future U.S. participation in an international cooperative program with the Federal Republic of Germany (FRG) for the development of thermal gas reactors. The contract further specifies that GE evaluate the differences in nuclear licensing between the U.S. and the FRG with a view towards the impact of such differences upon the conduct of an international program.

As a consequence of the above considerations, General Electric has conducted an investigation of the participants, procedures, and technical requirements of nuclear plant licensing in the FRG. The nuclear licensing in the two countries has been compared and those differences generating possible problems in the cooperative development of thermal gas reactors have been identified. Resolution of licensing differences is included as an integral part of the international program management plan; however, some general solutions are suggested in Section 6 .

\subsection{BACKGROUND}

Comparing the nuclear licensing program of Germany with that of the U.S. could not be performed by simply evaluating the differences between specific requirements. As will be shown, the German approach is more complicated than that of the U.S. and in some respects fundamentally different. Therefore, it was important that the comparison of technical and administrative requirements be founded upon a detailed understanding of the German organizations involved (and their interrelationships), the legal basis of licensing requirements, and the procedures followed during 1icensing. 
In order to obtain a clear picture of the organizations, meetings were conducted with the major participants. Information presented in this report is based upon both discussions with German personnel and review of descriptive FRG documents. A listing of documents utilized is presented in Section 7.

\subsection{U.S. NUCLEAR L ICENSING}

It is assumed that the reader has a basic understanding of nuclear licensing in the United States; however, a brief description is provided below. More complete discussions are provided in other documents, such as those found in References 1 and 2.

The Federal Government has the responsibility for virtually all aspects of nuclear licensing. The U.S. Nuclear Regulatory Commission (NRC) is the centralized regulatory body for the nuclear licensing process. Figure 1-1 is an organization chart of the NRC. Of particular interest to the present study are the Office of Nuclear Reactor Regulation and the office of Standards Development, which deal with licensing technical reviews and development of technical requirements, respectively. The NRC derives its authority from two Federal statutes. Under the Energy Reorganization Act of 1974, NRC became responsible. for implementing the regulatory requirements of the Atomic Energy Act of 1954, as amended. The NRC is also responsible for the environmental reviews for nuclear facilities under the National Environmental Policy Act (NEPA) of 1969.

The licensing of a nuclear power plant in the U.S. is comprised of essentially two steps: construction permit (CP) proceedings and operating license (OL) proceedings. The two stages are centered on submittal of the Preliminary Safety Analysis Report (PSAR) and the Final Safety Analysis Report (FSAR) for the $\mathrm{CP}$ and the OL proceedings, respectively. :The review processes for these two stages are similar, and Figure 1-2 shows a simplified flow sheet for the CP review: (1)*

*Footnotes refer to references listed in Section 7 : 


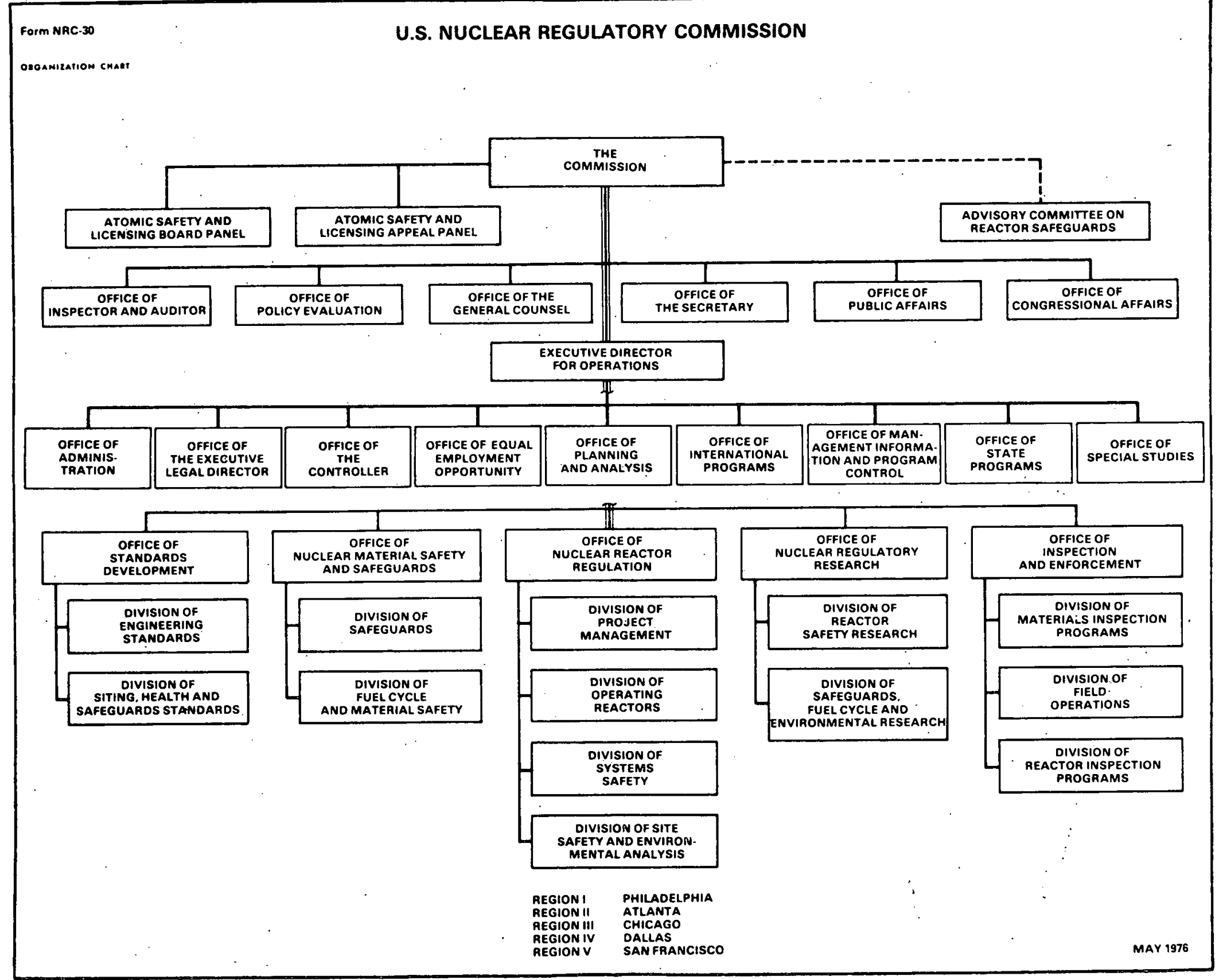

Figure 1-1. U.S. Nuclear Regulatory Commission 


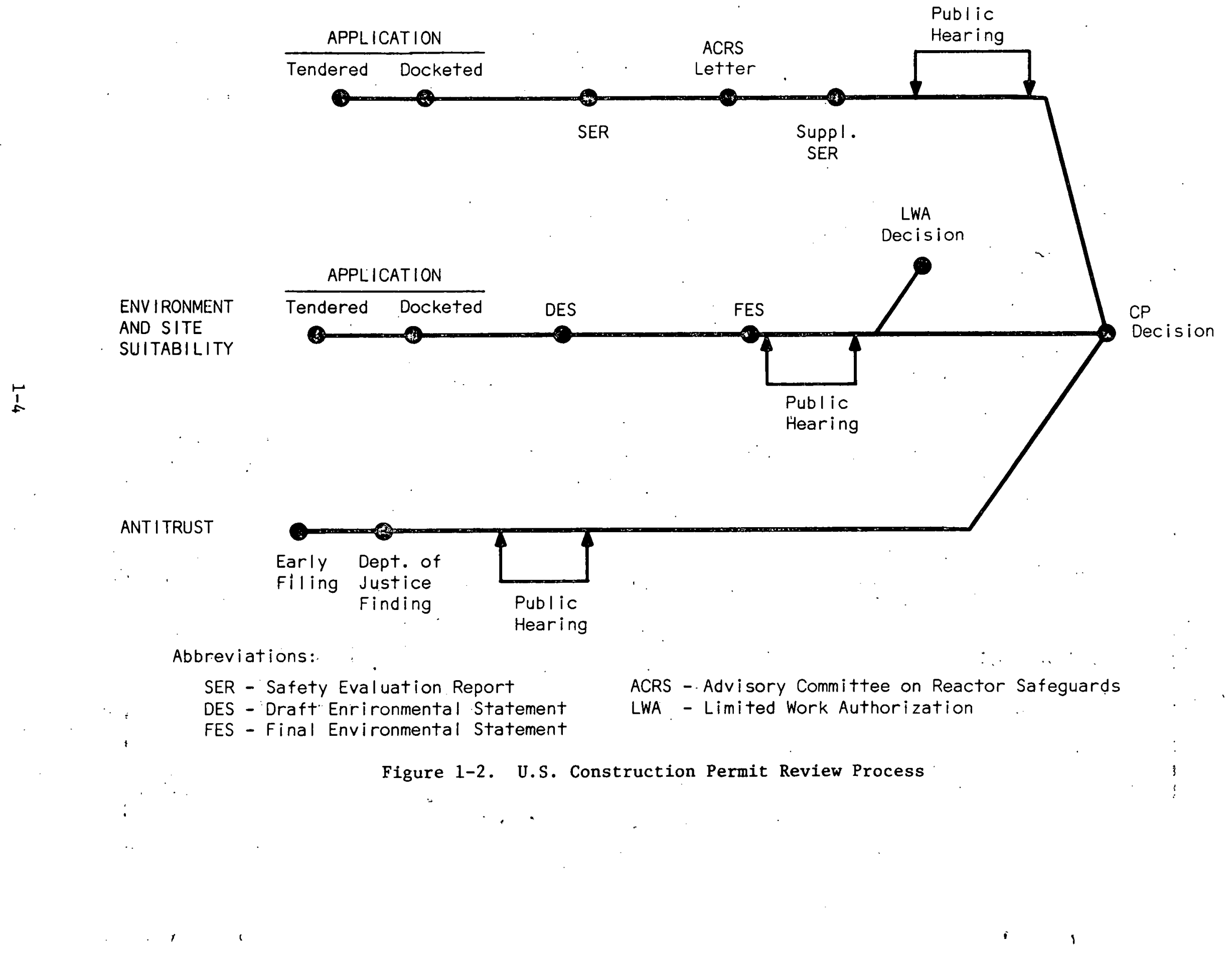


The fundamental statute implementing the Atomic Energy Act is Title 10 of the Code of Federal Regulations (10CFR). Parts of particular interest are: 10CFR Part 20 (10CFR20) "Rules for Protection Against Radiation," 10CFR50 "Licensing of Production and Utilization Facilities," and 10CFR100 "Reactor Site Criteria." 10CFR50 provides the bastc technical guidance for the design of nuclear power plants, both in its body and in a series of appendices. 10CFR50 Appendix $A$ is a listing of the "General Design Criteria for Nuclear Power Plants" or GDC's. Note that these GDC's have the force of law behind them.

The basic requirements are expanded and/or interpreted by other documents issued by the NRC. The NRC Regulatory Guides are guidelines without the force of law, providing direction for meeting the regulations and may describe an acceptable solution. In order to standardize the safety reviews of license applications, NRC has issued Standard Review Plans (SRP's) which describe the basis of NRC technical reviews. Environmental SRP's (ESRP's) are currently being prepared for NRC technical reviews of environmental matters. Neither Review Plan has the force of law. However, they do have strength since they are the bases for the NRC technical review and deviations will delay the time-consuming licensing process with accompanying cost penalties.

A non-regulatory source of technical criteria for nuclear plants is the consensus standards developed by industry with participation by the NRC staff. These standards are usually issued by the Amercian National Standards Institute (ANSI) after being prepared by working groups within the framework of professional socleties, such as the American Society of Mechanical Englneers (ASME), the American Nuclear Society (ANS), or the Institute of Electrical and Electronics Engineers (IEEE). Some industry-prepared documents have become central technical criteria actually having the force of law in the various states and in the criteria of 10CFR (e.g., the ASME Boiler Code). Other standards may be accepted and endorsed by NRC in Regulatory Guides.

\subsection{REPORT SUMMARY}

The content of this report is organized to provide first a detalled picture of the German nuclear licensing infrastructure, followed by a 
summary of the German regulations for light water reactors. The status of implementing existing German and U.S. regulations on gas reactors is then described. Finally, conclusions are drawn as to the impact of nuclear licensing differences on an international program. Appendix A, prepared by NUS Corporation of Rockville, Maryland, under subcontract to Generai Electric Company, provides a detailed discussion of the technical requirements. 
SECTION 2

WEST GERMAN NUCLEAR LICENSING FRAMEWORK

\subsection{BACKGROUND AND GENERAL DISCUSSION}

The Federal Republic of Germany (FRG) is organized into political units that appear at first glance to be structured in a manner similar to that of the United States. There is a Federal Government located in Bonn and eleven states, including the City-State of Berlin. Upon closer scrutiny, however, it becomes clear that certain fundamental differences between the FRG and the United States exist.

The FRG is a centralized confederacy made up of eleven "Länder." For convenience the German word "Land" is translated into the English. word "state" instead of the more correct word "country.": This obscures the fact that the German Länder are quasi-autonomous countries with greater authority and political power than their counterparts in the U.S. Historically Germany was made up of numerous countries that were, until the last century, independent sovereign states. That historical precedent has been preserved in the FRG in the strength of the eleven existing states (the word "state" will be used in this report to be consistent with current practice, but the reader is cautioned to realize that there is a difference). This autonomy does not extend to all areas (e.g., national defense).

The political strength of the German states has been manifested in the nuclear licensing process in the central role assumed by the State Supreme Licensing Authortties. The applicant for a nuclear facility license applies to the Supreme Licensing Authority of the State where the facility will be located. That State then coordinates the licensing proceeding and ultimately issues the license within the broad constraints of the German Atomic Law. The State Supreme Licensing Authorities place 
heavy reliance upon outside experts to conduct the technical review of license applications. The supervision of operating plants is conducted by the State Supervising Authorities.

The States do not, however, implement and enforce the Atomic Law (a Federal statute) completely autonomously. The Federal Government has the responsibility and authority under the Atomic Law to ensure State compliance with the law and to coordinate the activities of the various States to obtain consistency. The task of acting as the Federal supervisor of nuclear licensing was assigned to the Federal Ministry of the Interior (BMI). Although the BMI nuclear staff is larger than that of a typical Supreme Licensing Authority, they must still make use of outside technical experts for much of their technical work. In addition to outside technical companies, BMI makes continuing use of an advisory body of about fifteen senior scientists and engineers very similar in nature to the U.S. Advisory Committee on Reactor Safeguards (ACRS). This advisory committee, called the Reactor Safety Commission (RSK), reviews each license application as well as generic safety issues. There is also a Radiation Protection Commission (SSK) that performs a similar advisory function in radiation protection matters.

As mentioned above, both the Supreme Licensing Authority and the BMI make use of outside technical experts during license proceedings. Each of the States has a private but nonprofit company of technical experts called a Technical Inspection Agency (TUU). The TUV's have numerous functions from car inspections to boller certification, and most have a nuclear division which acts as expert for the nuclear licensing bodies. The TÜ''s coordinate their activities in the various States by the use of the Confederation of Technical Inspection Agencies (vdTüv).

The TÜ's formed a centralized Institute for Reactor Safety (IRS) to support the various TÜV's on special nuclear topics, such as accident analysis. The IRS was reorganized in January 1977 and renamed the Company for Reactor Safety (GRS). The GRS is a nonprofit private company that today performs technical contracts for the various Tü's, the Supreme 
Licensing Authorities, the BMI, and the RSK. Other organizations having an impact on German nuclear licensing criteria include the Landerausschuss fur Atomkernenergie (State Committee for Nuclear Energy), the Nuclear Standards Commission (KTA), and the German Institute for Standardization (DIN). The first organization is a coordination body of the States and the BMI, while the latter two deal with the development of standards.

This brief introduction provides a summary description of the major participants in the German nuclear licensing process. The following sections will describe in detail these as well as other organizations and attempt to demonstrate clearly the conduct of the licensing process. Figure $2-1$ is a simplified flow sheet that depicts the overall licensing scheme. Note the simultaneous reviews by the Supreme Licensing Authority with its experts and the BMI with its experts.

\subsection{STATE SUPREME LICENSING AUTHORITIES}

The Länder (States) of Germany are the regulatory bodies for nuclear facilities within their domain. The Atomic Law is implemented by the various States on behalf of the Federal Government.

Each State itself determines which of its ministries is to be assigned as the "competent authority" for nuclear licensing. This "competent authority" then acts as the Supreme Licensing Authority for the geographical area of that State. In some cases, more than one ministry may be so designated. A specific example is the State of Nordrhein-Westfalen (centered in Düsseldorf) where the Ministerium für Arbeit, Gesundheit, und Soziales (Ministry of Labor, Health, and Social Affairs) and the Ministerium für Wirtschaft, Mittelstand, und Verkehr (Ministry for Economics, Small Business, and Transport) have been jointly designated the Supreme Licensing Authority.

A Supreme Licensing Authority usually has a small staff of technical, legal, and managerial personnel that coordinates the nuclear licensing proceedings within the state. Thus it is a necessary and fundamental aspect of German licensing that the Supreme Licensing Authorities rely upon outside consultants for expert opinions. This 


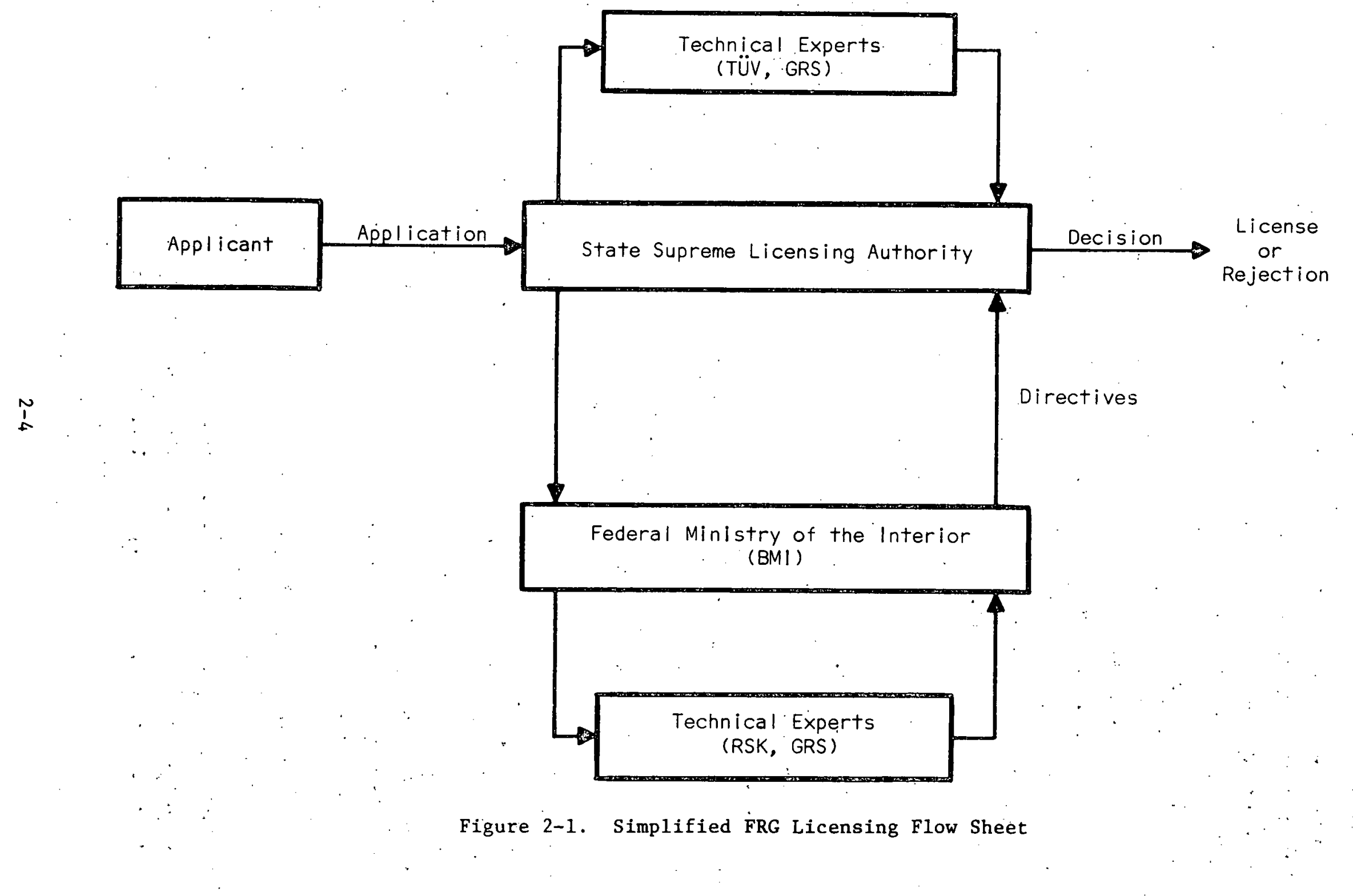


does not relleve the States of their responsibility to make their own decisions. Although each State normally calls upon its State TUV for technical experts during a given licensing proceeding, it is completely free to select other organizations as competent experts. In some cases a State may call upon the TüV of another State when that group is felt to be more competent. The State of Hessen, for example, utilizes the TUV in Bavaria for nuclear matters due to the small size of the Hessen TÜ. The State is greatly concerned with the objectivity and independence of its experts and may ensure objectivity by breaking up the technical review. For example, if a TUV had performed technical work for the licensee in a certain area, the Licensing Authority might take review of that work out of the TÜV contract and give it to another expert organization. Although the Licensing Authority relies upon the TÜV and the GRS as experts, it is normal practice for special questions to be assigned to such groups as the "Bundesanstalt für Gerwässerkunde (Federal Institute for Hydrography), the "Bundesforschungsanstalt für Fischerei" (Federal Institute for Fishery Research), or the "Bundesanstalt für Materialprüfung". (Federal Institute for Materials Testing). Scientists from universities, doctors, experts on petrochemical installations, fire fighting experts, and others have also been appointed.

The individual States have issued some administrative guidelines for the handling of nuclear matters within their domains; however, most State administrative and technical guides are developed and issued within the framework of the Länderausschuss (see Section 2.5), a committee made up of the State Authorities and the BMI. The States also participate in the Nuclear Standards Commission (KTA) (see Section 2.11).

The Supreme Licensing Authorities have the additional responsibility of coordinating the participation of other State and regional authorities and the public in licensing proceedings. There are other State authorities that may need to provide input to the licensing proceeding, such as planning authorities, building authorities, power authorities, water authorities, and environmental authorities. These other bodies that may have jurisdiction in a given licensing proceeding participate by reviewing : specific aspects of the proposed plant and providing consultation to the . Supreme licensing Authority. They also issue special licenses (e.g., water 
use is covered by a separate license). As will be discussed later, the involvement of the pubilic must be ensured by actions required of the Supreme Licensing Authority.

\subsection{STATE SUPERVISING AUTHORITIES}

The responsibility for state regulation of nuclear plants shifts to the State Supervising Authorities when the plants become operational. The Supervising Authority may. or may not be the same ministry that acts as the Licensing Authority. Since this paper is primarily concerned with design and construction requirements, the Supervising Authorities will not be described further.

\subsection{FEDERAL MINISTRY OF THE INTERIOR (BMI)}

Although the States have the task of acting as the Supreme Licensing Authorities for nuclear licensing proceedings, the Federal Government in the form of the BMI (Bundesminesterium des Innern) has the responsibility for overall supervision of the States. Within the guidance of the Atomic Law are the following requirements:

- The issuance of statutory ordinances remains the province of the Federal Government (i.e., BMI).

- The State Supreme Licensing Authorities are subject to and bound by the directives of the Federal authority (i.e., BMI).

- The Federal supervision of nuclear licensing covers the legality and technical adequacy of the State licensing proceedings.

- The Federal Government can request reports and relevant documents (i.e., related to the State licensing proceedings, such as safety reports).

The implementation of these broad guidelines has resulted in the creation of a nuclear licensing supervisory staff at the BMI. The staff of BMI involved with nuclear energy and radiation protection act as technical managers and overseers of the licensing program. The organization of BMI related to nuclear energy is outlined in Figure 2-2. The seven Referats 


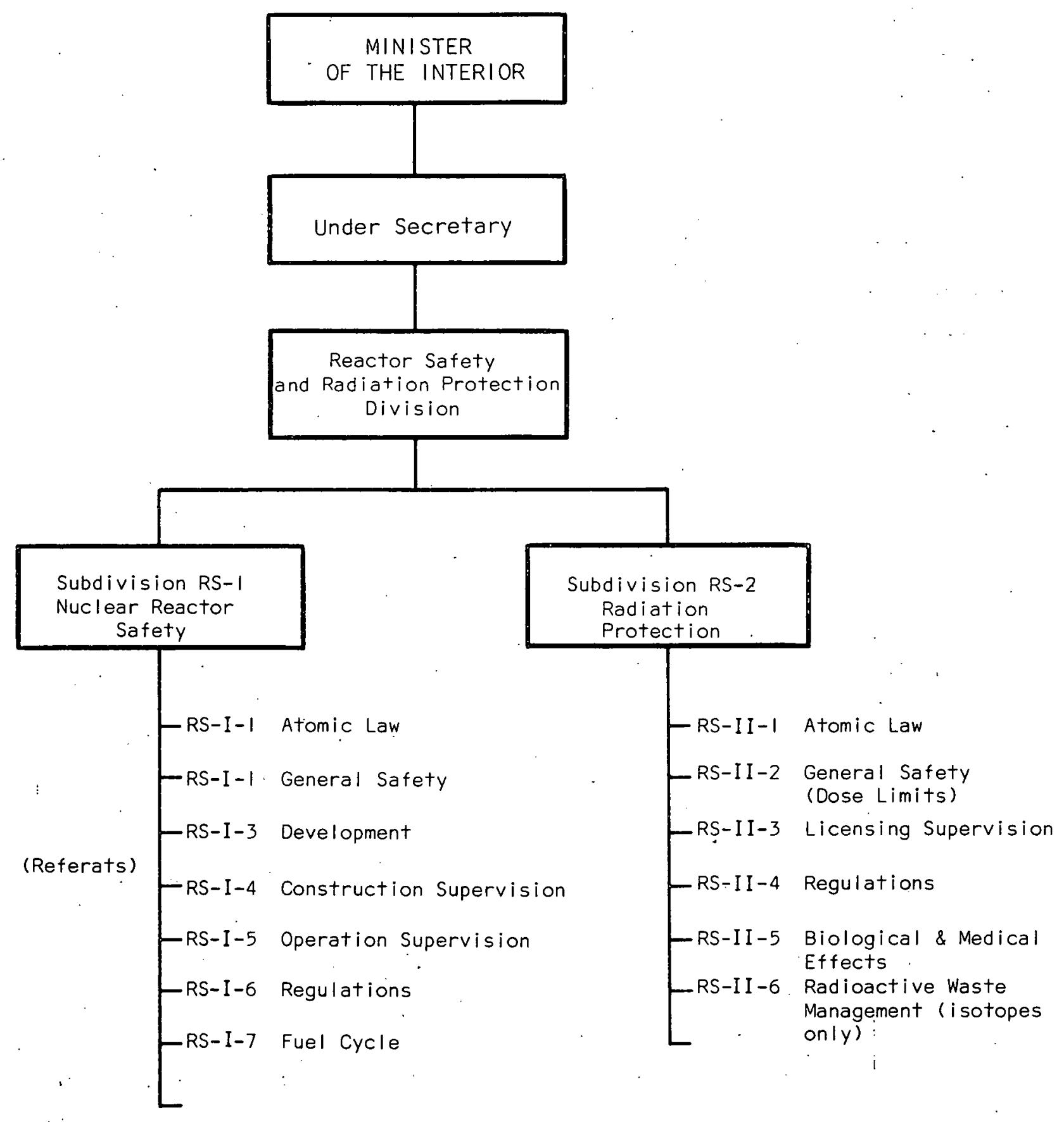

Figure 2-2. Federal Ministry of the Interior (BMI) 
or "Sections" of the Nuclear Reactor Safety Subdivision are staffed with senior personnel tasked with supervision of all non-radiation protection aspects of nuclear regulation.

The Atomic Law Section (RS-I-1) is responsible for legal supervision of the State licensing proceedings (e.g., license applications and public hearing conduct). The General Safety Section (RS-I-2) deals with broad aspects of nuclear safety such as international affairs, public acceptance, and generic safety issues. The Development Section (RS-I-3) acts as the central coordinator for regulatory research and development. Currently over one hundred research programs are under way in such areas as generic safety issues, maximum hypothetical accident calculations, and code improvements.

The two supervision sections (RS-I-4, RS-I-5) are the liçensing supervisors for construction and operation of nuclear facilities, respectively. These sections assign project managers to oversee the licensing proceedings of currently pending applications and operating facilities. They also coordinate the Federal review activities and interface with the RSK.

The Regulations Section (RS-I-6) handles the Federal activities in the development of regulations, codes, standards, and other licensing guidelines. The section is responsible for management control of this work, which is generally conducted outside of BMI at the GRS or KTA. The last nuclear section (RS-I-7) supervises Federal activities in the fuel cycle (except reactors) such as fuel fabrication, waste storage, and reprocessing.

The BMI staff calls upon outside technical experts in the same way as do the State Supreme Licensing Authorities. For special technical questions, the GRS may perform the work, or other private companies could be contracted. The RSK and SSK act as advisory bodies for the BMI during Federal participation in nuclear licensing proceedings.

BMI has a number of duties related to nuclear. Iicensing other than their participation in each individual license proceeding. One area mentioned briefly above is regulatory research. BMI coordinates 
research programs in support of safety questions generated during licensing and operation of nuclear facilities. Since 1972, when nuclear regulation was separated from nuclear promotion, the Bundesministerium für Forschung und Technologie (Federal Ministry for Research and Technology or BMFT) has had the responsibility for energy research and development activities. The BMI Referat RS-I-3 acts as liason between BMFT and BMI in nuclear research and development to ensure consistency and avoid duplication of efforts.

In the area of regulations, BMI is very active in the development of new or revised guideline documents, whether ordinances or standards. BMI participation in the standards developed by the Nuclear Standards Commission (KTA) is in review and approval activities rather than in the drafting efforts (see Section 2.9). BMI issues guidance to the State Supreme Licensing Authorities, technical experts, and to industry when a vacuum exists in the current regulations and certain other conditions exist. Specifically, BMI would issue such guidance when the KTA is not working on a standard to fill the vacuum, when industry cannot achieve consensus on a standard due to controversy, or when industry does not agree with the BMI that a need for a requirement exists. In general the BMI would draft its position and issue it within the framework of the Länderausschuss (see Section 2.5), although on rare occasions BMI will issue a position unilaterally, such as the recent BMI position on external explosion protection.

\subsection{THE STATE COMMITTEE FOR NUCLEAR ENERGY (LÄNDERAUSSCHUSS)}

Due to the decentralized nature of the German licensing framework, a need exists for coordination between the various State Supreme Licensing Authorities and the Federal regulatory group (BMI). This need is filled by the Länderausschuss für Atomkernenergie (State Committee for Nuclear Energy), a body made up of the Supreme Licensing Authorities, State Supervising Authorities, and the BMI.

Guidelines developed or approved by the Länderausschuss are given significant force, even though such guidelines are not legally binding. This force exists since the approval indicates agreement between the various states and the Federal Government to utilize the guidelines as bases for their licensing reviews. The best known guidelines approved 
by the Landerausschuss are the German "Safety Criteria for Nuclear Power " Plants" issued in 1974. These criteria, described in detail in Section 4 and in Appendix A to this report, are generic in nature, although other . issuances are very detailed. Guidelines of the Länderausschuss generally deal with non-technical subjects such as sabotage protection and operation qualification. When a disagreement exists between industry and government as to the need for a particular guide, the Landerausschuss may step in and issue the guide, as discussed in Section 2.4:

\subsection{TECHNICAL INSPECTION AGENCIES (TtV'S)}

The Federal Republic of Germany is the home of eleven Technische Überwachungs-Vereine (TÜV's), spread over the FRG. The TÜV's are German phenomena that have been in existence for over one hundred years. These Technical Inspection Agencies are private self-financing (but non-profit) organizations originally created by industrial enterprises in order to prevent the widespread accidents at steam boilers (The ASME boiler and pressure vessel code has a similar history in our own country). As the success of the TÜ's became known, the States terminated their own inspection efforts and instead delegated these activities to the TU'v's. Through the years, the scope of work entrusted to the TüV's has increased to include inspection and testing of virtually all hazardous technical installations. Today the activities of the TÜ''s are in the following three main fields: $(6)$

- Within the purview of the Gewerbeordnung (Trade Regulations), the testing and inspection of:

-lifting and hoisting equipment

-steam-boiler plants

-pressure vessels

-installations to draw off compressed or liquified gases or gases dissolved under pressure

-electric wiring and fittings in particularly hazardous rooms

-plping and tubing under internal pressure for combustible, caustic or poisonous gases, vapours, or liquids

-installations for the storage, drawing off and conveyance of combustible liquids

-materials and welding engineering 
- Tests and inspections within the purview of road-traffic legislation:

-type-approval testing of motor vehicles and their accessories

-safety tests on motor vehicles

-testing and examination of motor vehicle drivers and driving instructors

-aptitude tests in medico-psychological examination centers

- Tests, advisory activities, and expertise in other technical fields, e.g., for quality assurance:

-nuclear engineering, reactor safety, and protection against radiation

- conveyance engineering

-ropeways and "fair rides" (non-stationary structures)

-electrical engineering

-environmental protection (such as noise abatement, clean air, and sewage problems)

-installations for the storage, drawing off, and conveyance of liquids perilous to water

-technical chemistry

-tools and equipment

-heat and power engineering

-industrial medicine and safety engineering

-marine engineering

-testing of ships

-testing of materials

-mining

-motor vehicle inspection by mutual agreement

In order to accomplish such activities, the various Tự's staff over 11,000 people, including some 7,000 graduate engineers, graduate chemists, graduate physicists, medical doctors, psychologists, engineers, and technically trained assistants. Many of these people are "authorized inspectors," specially trained to inspect a broad range of technical facilities and activities, from pipe welds to private automobile safety and emmissions.

As nuclear energy became a viable source of electric power, seven of the TÜ's added nuclear engineering and radiation protection departments. At this time the TÜ''s without nuclear departments are Hessen, Saarland, Rheinland-Pfalz, and Berlin. The last ten years have seen real growth in the level of nuclear expertise possessed by the Tüv's. Typical organization charts for a nuclear TÜv are shown in Figures 2-3 and 2-4. The tasks assigned to a TüV by its Supreme Licensing Authority normally include the following: ${ }^{(7)}$ 


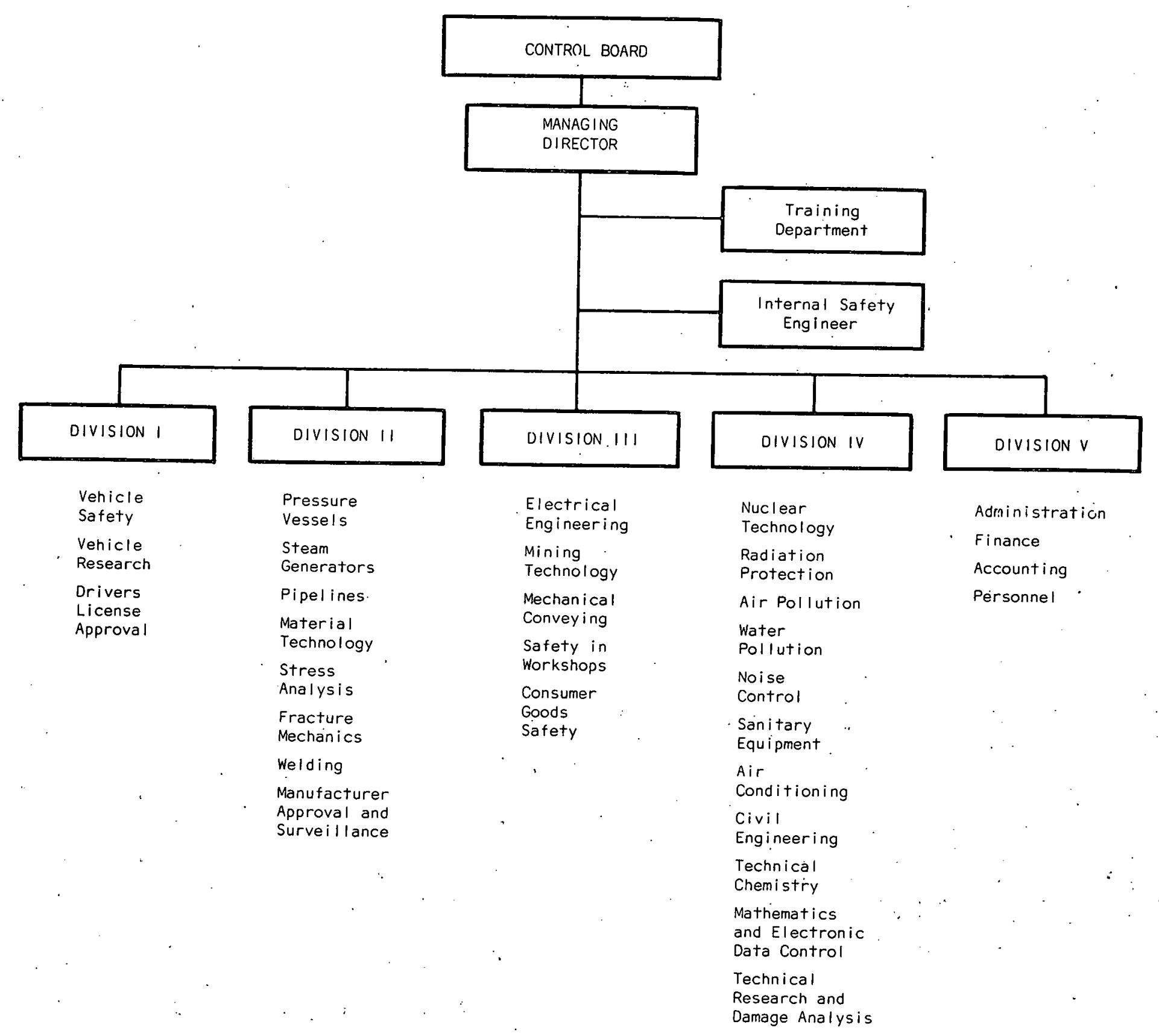

Figure 2-3. Typical TÜV Organization 


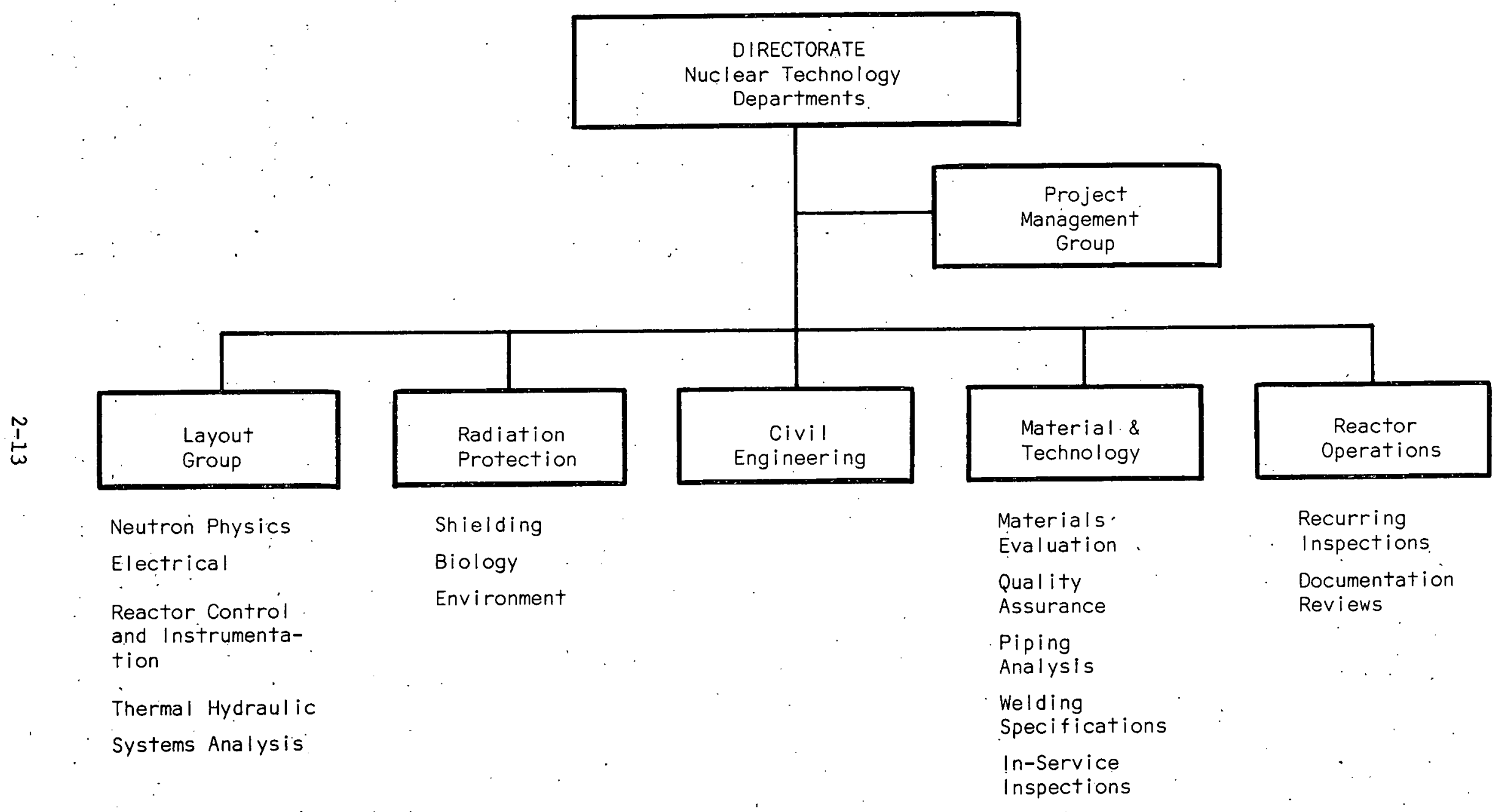

Figure 2-4. Typical TüV Nuclear Technology Department 
- Design and Construction Phase

-safety assessment

-design review

-examination of specifications

-examination of manufacturing documents

-manufacturing surveillance

- construction site surveillance

-preoperational tests

-records control

- Operation Phase

-recurring inspection tests on systems and components

-evaluation of changes and their control in nuclear

power plants

-damage analysis

-qualification of the operational staff

- Decommissioning Surveillance

During the design and construction phase the rüV is the expert consultant for the Supreme Licensing Authority and in this capacity acts as the central examiner of the licensiñg proceeding. As mentioned earlier, there exist eleven T"̈ل's and seven with nuclear activities. In order to ensure consistency between the various states, the eleven TU'V's and the GRS are members of the confederation of TÜV's (VdTÜ), which is discussed in Section 2.7. The activities of the cognizant TÜV during the licensing proceeding is broken into two categories, "Safety Assessment" and "Accompanying Control." Safety assessment means evaluations related to the design and preoperational testing of safety-related systems and components. These evaluations ascertain whether the systems and components meet the necessary requirements and whether they achieve the latest standards of knowledge and technology. This latter constraint is unique to the FRG Atomic Law and will be discussed in more depth in Section 4.2. The safety assessments also include theoretical examination of transient behavior during normal, upset, and accident conditions.

Accompanying control refers to TüV activities in evaluating system and component layout of the plant: The extent of accompanying control is specified by the contract with the Supreme Licensing Authority, but generally implies all safety-related systems (i.e., reactor vessel, reactor coolant system, radioactive systems, emergency systems, etc.). The activities associated with accompanying control ensure that each system, component, and part in question meets the requirements imposed by the 
safety assessment or by existing regulations. In the area of testing, accompanying control includes: ${ }^{(7)}$

- Design review and examination of manufacturing, functional test, and preoperational test documents

- Testing of materials, manufacturing surveillance, and pressure tests

- Construction site tests

- Functional and preoperational tests

- Documentation and records control

The Tüv activities during the design and construction phase appear more extensive than those of the U.S. N.R.C., since they not only perform a safety assessment and issue paper reviews of component manufacturing and testing, but actually go out to the manufacturer's factory and inspect every safety-related component. The TÜ's also recalculate the piping design margins for all safety-related systems instead of simply approving the analytical methods of the licensee. The technical expertise of the various TÜV's in nuclear topics depends upon the size of the particular TÜV and the number of nuclear facilities previously licensed in its state. The result of this situation is that the various TUV's do not all have the same expertise and must, therefore, call upon other TÜ's or the GRS for special assistance during licensing proceedings.

During the licensing phase, the Tül's plan out the inservice inspection (ISI) for safety-related systems and components. The ISI consists of non-destructive testing, pressure testing, functional testing, vessel irradiation evaluations, etc. During the operation phase, the TÜV's generally perform the inspections, but it depends upon the agreement with the Licensing and Supervising Authorities. As design changes are made to the plant during its lifetime, the TU'V's act as the technical consultants for the Supreme Licensing Authorities. in determining whether to allow. these changes. In the event of incidents at the plants, the Supreme Licensing and Supervising Authorities frequently appoint TUV',s as the post-incident investigators. Members of the TÜV's also serve on the Examination Committees for the qualification of plant operators. 
It should be pointed out that through the years the Tü's have developed detailed criteria for the conduct of their evaluations. Most of these criteria were generated prior to the Federal regulations and guidelines and the development of industry consensus standards. The completion of these latter documents has resulted in some changes in TÜV criteria in order to ensure consistency. Frequently TÜ's through the vdTü act as interpreters for the somewhat vague Federal regulations.

\subsection{CONFEDERATION OF TECHNICAL INSPECTION AGENCIES (VdTÜV)}

As detailed in the previous section, there are eleven TÜ's in Germany which perform a wide range of technical inspections. Each TÜV is an autonomous private company, yet all perform similar tasks. In order to coordinate the programs on a nationwide basis, the TÜV's are incorporated in the Vereinigung der Technischen Überwachungs-Vereine. e.v. (VdTÜV), which is located in Essen. There are five industrial enterprises, with their own inspecting offices to guarantee technical safety in their special areas. These "self-inspectors" are also members of the VdTüv. Examples of self-inspectors are Bayer and BASF.

The VdTÜV is important in ensuring consistency in the technical reviews performed by the various member TÜV's. In the complex area of nuclear license evaluations, the VdTüV provides assurance that the TÜV guidelines are uniformly imposed and acts as a forum for the development of new internal Tüv criteria.

\subsection{COMPANY FOR REACTOR SAFETY (GRS)}

The Gesellschaft fur Reaktorsicherheit - GRS (Company for Reactor Safety) has, as its predecessor the Institut fur Reaktorsicherheit der Technischen Überwachungs-Vereine (Institute for Reactor Safety of the Technical Inspection Agencies-IRS). In 1965 the TÜV's recognized, due to the specialized nature of nuclear technology; that a centralized institute, specializing in nuclear matters, would be a useful adjunct to the existing TUtV nuclear departments. The result of this realization was the creation of the IRS to support the technical aspects of the TÜ's and provide assistance to the Federal Government. As in the case of TUV's, the IRS was a private nonprofit company. The IRS began its 
existence with a small staff assigned the following tasks:

- Working out safety codes and guides, and expert comments on basic safety questions, taking into account the members' expertise.

- Advice and expert consultancy for Federal German authorities and their authorized institutions.

- Participation in the preparation of expert evaluations by members.

- Exchanging experiences with members.

It is interesting to note that the concept of a centralized group of reactor experts actually goes back to 1961, when the VdTÜ created the Arbeitsgruppe für Reaktorsicherheit (Working Group for Reactor Safety) to provide technical support for the RSK. During the period 1961-1965 the Arbeitsgruppe performed eighteen large evaluations; including the Gundremmingen nuclear station.

When the IRS was formed, the Federal Ministry for Scientific Research, which existed at that time, agreed to subsidize the operation of the IRS for ten years. During those ten years the IRS grew both in physical size and in scope of activity. By the end of 1974, the IRS employed about 160 people and had expanded its primary function as expert consultant for the TÜ's to a much stronger role as expert for the RSK, the Supreme Licensing Authorities, and the Federal Government. In January 1977 the IRS merged with the Laboratorium für Reaktorregelung und Anlagensicherung-LRA (Laboratory for Reactor Control and Plant Safety) at the. Technische Universität Munchen (Technical University of Munich) and became the GRS. The merger joined under common management the expert evaluation strength of the IRS with the research and development strength of the LRA (primarily related to analysis techniques, computer code development, post-accident behavior, etc.). Today the GRS numbers approximately 400 people.

The organization of the GRS, appearing on Figure 2-5, displays the overall structure of the Munich and Cologne offices, formerly the LRA and IRS offices, respectively. The Secretariats for the Reactor Safety Commission (RSK) and the Radiation Protection Colmission (SSK) 


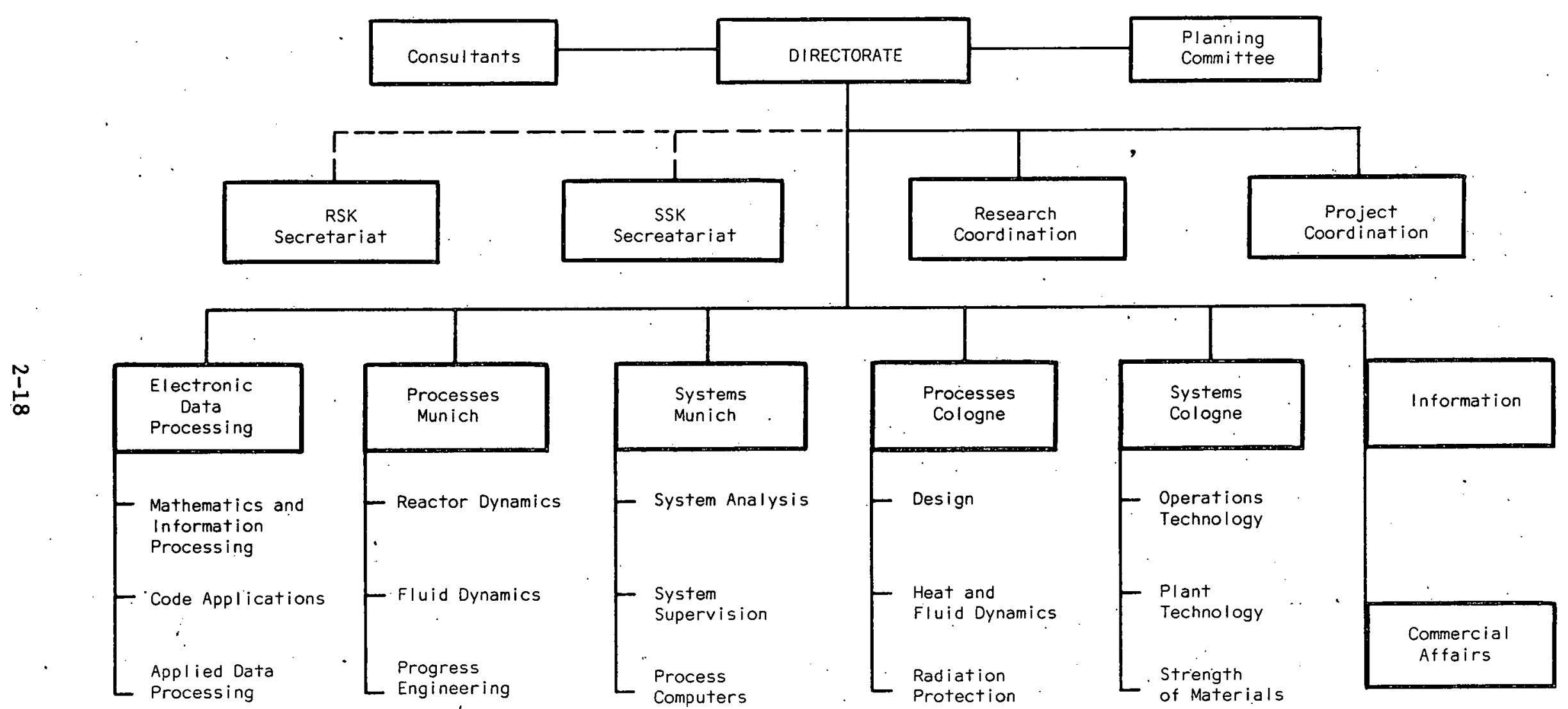

Figure 2-5. GRS Organization 
are located at the GRS-Cologne but have only administrative ties to GRS management.

The structure of the Munich and Cologne offices is quite similar. The main difference is that Munich is responsible for long-term development of computer codes and analysis methods, whereas Cologne is responsible for applications (i.e., expert consultation work). In order to better appreciate the capabilities of GRS, brief descriptions of the various departments are provided below.

As a general rule the Systems Divisions are involved with static analyses such as maximum stresses. The Processes Divisions are more .involved with transient or dynamic behavior. The Electronic Data Processing Division is made up of three departments. The Mathematics and Data Processing Department is located in Munich and provides methods and codes using a staff of numerical analysts. The Code Applications Department is in Munich and services that office only. Main responsibilities are program implementation, input description preparation, and providing specialists for the various IBM and CDC machines. The Applied Data Processing Department in Cologne develops improved codes, provides applied mathematics assistance for Cologne Divisions, and services the computer linkup with the Nuclear Research Center (KFA) in Jullich.

Processes-Munich includes the Reactor Dynamics Section, which develops new models in the areas of reactor physics, plant dynamics, and heat transfer. The Fluid Dynamics Section is tasked with advanced analyses of severe accidents and includes special groups for pressure wave analysis, blowdown, and reflood. The Process Engineering Section studies containment behavior and fuel cycles.

Systems-Munich is made up of three sections. The System Analysis Section looks at probabilistic methods, system reliability, and component reliability. Systems Supervision includes structural behavior analyses, noise monitoring, and measurements, tests, and procedures. Finally, the Process Computers Section evaluates the risks associated with failures in the plant control systems. 
The Processes and Systems Divisions located in Cologne are directly involved in the expert consultation functions, which include: detailed verification of an applicant's analyses. The Design Department conducts nuclear design analysis for static conditions in addition to reactor and plant dynamic calculations. The Heat and Fluid Dynamics Department analyzes plant behavior during loss-of-coolant accidents, using the Blowdown Group, the Emergency Cooling Group, and the Containment Response Group.

The Radiation Protection Department is responsible for the analysis and evaluation of the following problem areas:

- Production, release, and transport of radioactive materials in nuclear installations.

- Effects of releasing radioactive materials in exhaust air and waste water during normal operation, including the questions of radiology and radio-ecology.

- Emission of fission products under accident conditions. and their radiological consequences.

- Handling, storage, transport, and reprocessing of nuclear fuels and their inherent risks.

- Removal of gaseous, liquid and solid radioactive waste. The Operations Department has responsibility for analysis of plant accidents, including:

- Natural effects such as floods, tidal waves, earthquakes, earthslips, lightning, and the effects of biological organisms.

- Man-made effects such as chemical explosions, pressure waves, aircraft crash, toxic gases, fires, mining subsidence, and sabotage.

The man-made hazards (particularly aircraft impact) are closely examined, in Germany due to the high population density. Computer programs have been developed for use in the licensing proceedings to calculate such effects as: ${ }^{(8)}$ 
- Penetration of structures by crashing aircraft parts

- Effect of debris on structures

- Effect of pressure valves

- Vibration of structures due to earthquake

- Loads due to vibration

The Reliability Group of the Operations Department reflects an increasing German use of reliability criteria in the licensing process. Fault tree analyses are an integral part of the GRS procedure. Singlefailure criteria are imposed, including passive failures, as a first level. This deterministic approach is followed by the probabilistic reliability approach.

The Plant Technology Department includes civil engineering of structures and buildings and analysis of process systems. The final technical department is the Strength of Materials Department, which performs stress analyses and develops materials test programs.

The Project Coordination Group provides project managers for the various expert consulation assignments. These project managers coordinate the technical reviews within the various other departments of the GRS. The GRS is very much involved in the licensing process, as discussed in other sections. Figure 2-6 shows the licensing process from the perspective of GRS participation, and. Figure 2-7 shows the technical reviews performed up through 1975. The project managers are the central coordinators of these activities.

The presence of a Research Coordination Department reflects the role of GRS in coordinating nuclear safety research programs under the auspices of the Federal Ministry of Research and Technology (BMFT). The Department was assigned the following four tasks: ${ }^{(8)}$

- Technical and organizational planning of the fast and effective implementation of a given overall program, with attention being devoted to the aspect of optimum participation of all appropriate agencies. 


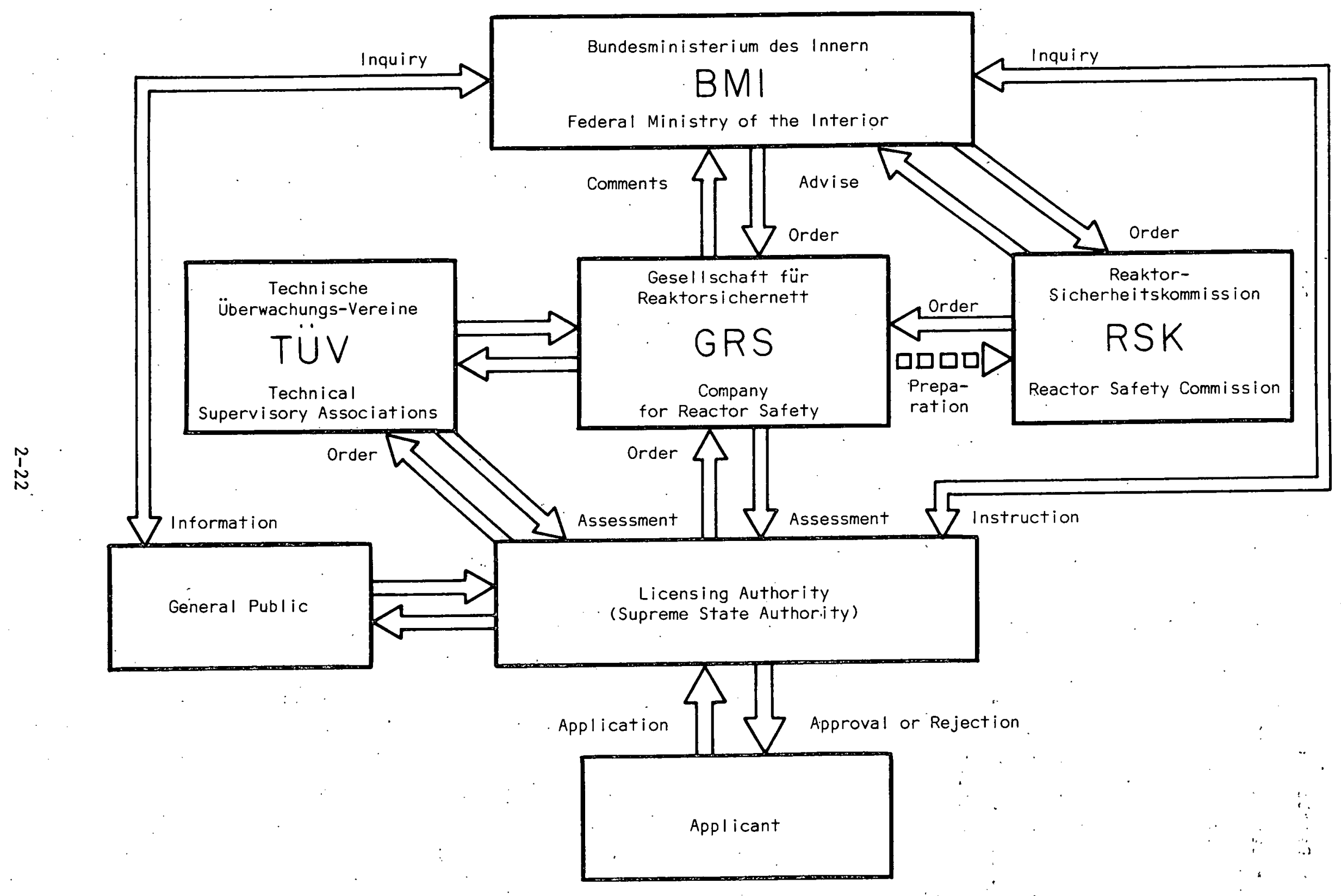

Figure 2-6. GRS Perspective of the Licensing Process 


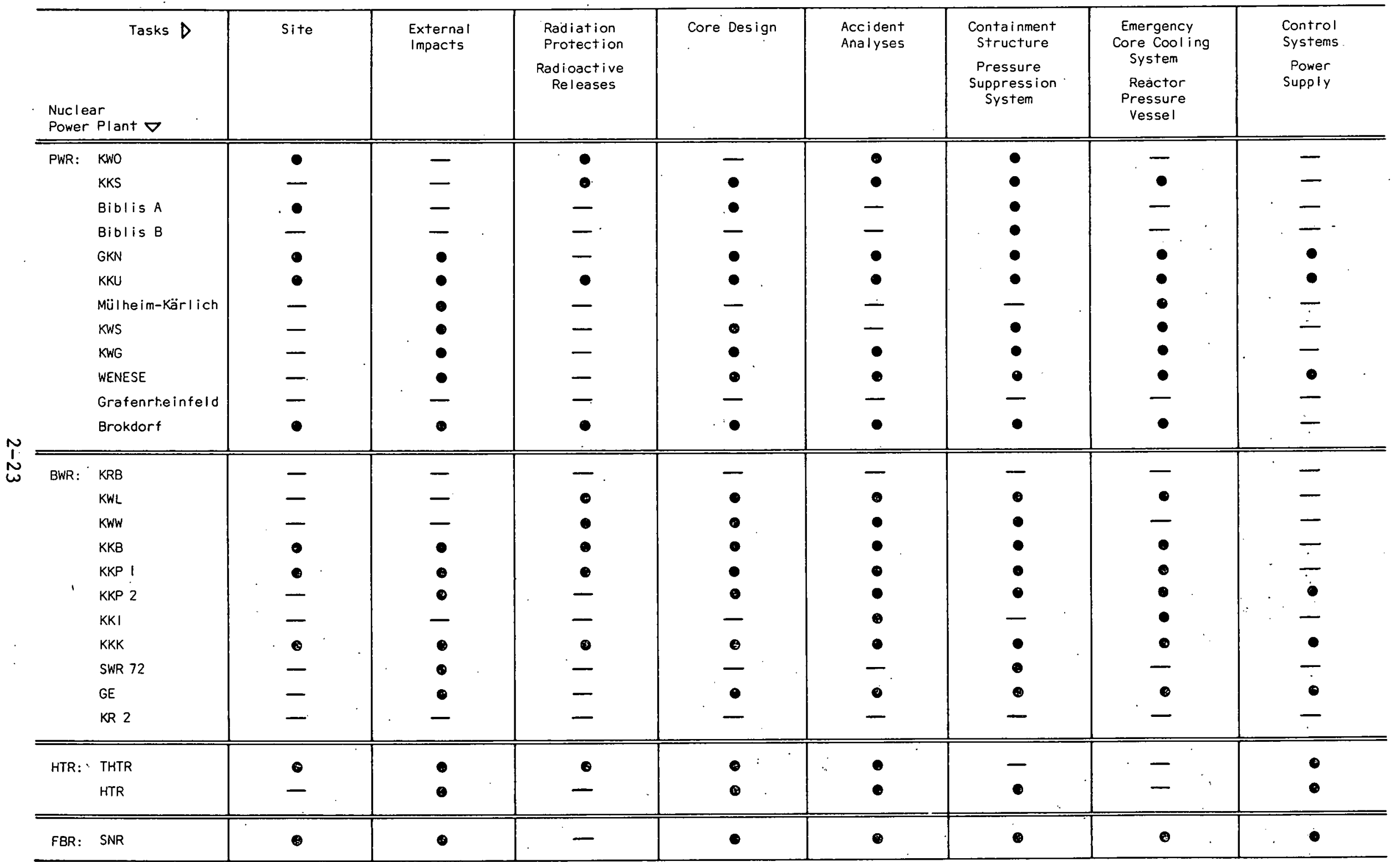

Figure 2-7. GRS Expert Evaluations 
- Technical supervision and timely financial auditing of the. implementation of research projects and tasks, while keeping to the overall objective for all projects and tasks, setting individual objectives, making estimates for end dates and costs.

- Systematic documentation of information and fast transmission of items of information to interested agencies at home and . abroad.

- Coordination of international agreements for planning and performance of research projects and tests, with central control of information flow.

\subsection{REACTOR SAFETY COMMISSION (RSK)}

The Reaktor Sicherheitskommission (RSK) was originally created as the expert advisor for the Federal Ministry for Education and Science (BMBW) in the 1960's. In 1972, when the BMI was designated the Federal ministry responsible for nuclear regulation, the RSK was reorganized as the chief consultant for that ministry in matters of nuclear installation safety.

The members of the RSK are selected from technical institutions and industry in order to ensure representation of at least the following areas of expertise: (5)

Reactor operation
Machine and apparatus
construction
Thermodynamics
Process engineering
Materials technology
Civil engineering
Measurements and control

Reactor physics

Electrical engineering Reactor chemistry Radiation protection Environmental protection Radiation biology Radiation medicine 
The membership normally consists of eighteen experts whose appointment is honorary and personal in nature. The members act independently and do not represent the firms or organizations to which they belong. In general it was intended that RSK would examine for the BMI new and unreviewed safety questions as well as the broad and generic safety problems. In practice, the RSK has reviewed every reactor license application in some detail. In order to provide licensees with guidance on the bases of their reviews, the RSK issued in 1974 a set of "RSK Guidelines for Pressurized Water Reactors," which are discussed further in Section 4.5.

The RSK can and does set up subcommittees to discuss special topics in preparation for the full RSK meetings. In addition to the presence of RSK members on the various subcommittees, specialists are widely utilized. Although the main RSK meets monthly (except for July and August), the subcommittees meet as needed. The summary below provides a view of subcommittee activities during 1971 through 1974, as well as the titles of major groups: ${ }^{(8)}$

\begin{tabular}{|c|c|c|c|c|}
\hline \multirow{2}{*}{ Subcommittee } & \multicolumn{4}{|c|}{ Meetings } \\
\hline & 1971 & 1972 & 1973 & 1974 \\
\hline Pressurized Water Reactors & 1 & 4 & 6 & 5 \\
\hline Boiling Water Reactors & 2 & 23 & 5 & 7 \\
\hline Sodium-Cooled Reactors & 4 & 9 & 10 & 3 \\
\hline High Temperature Reactors & -- & 2 & 2 & 2 \\
\hline BASF & -- & 3 & 6 & 2 \\
\hline Reactor Pressure Vessels & 1 & 6 & 9 & 9 \\
\hline Pressure Boundary & -- & -- & 5 & -- \\
\hline Emergency Cooling & 1 & 2 & 3 & 3 \\
\hline Chemical Reactions & 1 & 2 & 3 & 2 \\
\hline Fission Product Retention & -- & - & -- & -- \\
\hline Electrical Equipment & -- & 1 & 1 & -- \\
\hline Civil Engineering & 1 & $\because$ & 1 & 2 \\
\hline
\end{tabular}




\begin{tabular}{|c|c|c|c|c|}
\hline Subcommittee (Cont'd) & $\begin{array}{c}\mathrm{Me} \\
1.971 \\
\end{array}$ & $\begin{array}{r}\text { tings } \\
1972 \\
\end{array}$ & $\begin{array}{c}\text { (Cont 'd) } \\
1973 \\
\end{array}$ & $\underline{1974}$ \\
\hline Chemical Explosions & -- & 1 & 2 . & 1 \\
\hline Site Questions & 1 & 2 & 2 & 2 \\
\hline Reactor Operation & -- & 6 & 3 & 2 \\
\hline Backfitting & -- & -- & 1 & - \\
\hline Fuel Cycle & 1 & $\underline{2}$ & 2 & 3 \\
\hline $\begin{array}{l}\text { Total Subcommittee } \\
\text { Meetings }\end{array}$ & 13 & 63 & 61 & 43 \\
\hline
\end{tabular}

In support of the work of the RSK, a Secretariat was created as an independent organization located at the GRS-Cologne. It reports administratively to the GRS management (See Figure 2-5). Both BMI and.GRS managements have agreed that the chairman of the RSK has the responsibility for assigning the type and priority of the technical work of the Secretariat (in close cooperation with the BMI). The Secretariat (Geschaftsstelle) of the RSK consists of about ten full time staff members who provide technical support and perform administrative duties for the RSK, as summarized below: ${ }^{(8)}$

- Preparation and administration of all RSK meetings and of those of its subcommittees.

- Preparation of all important information for RSK examination in concentrated form.

- Further and selective information distribution or preparation of detalled analyses for certain questions at the request of individual RSK members.

- Submission of decision proposals to the RSK, taking into consideration the expert evaluations of the T"UV, the GRS, and its own examinations. The proposals would include compilations of all important issues involved in the decisions, identification of possible decision alternatives, and recommended decisions.

- Preparation of proceedings and compilation of all decisions suitable for publication giving the reasons for the decisions. 
Figure 2-8 shows the flow of information during a licensing proceeding from the perspective of the RSK. The Secretariat acts as the coordinator of RSK involvement. Copies of safety analysis reports are sent to the Secretariat and the Subcommittees by the applicant, as are the evaluation reports of the technical experts. If needed, the RSK may request additional reviews to be performed by the experts. In order to expedite technical review, the subcommittees can request added work or information directly from the applicant rather than wait for the formal paperwork flow path. After its review, the RSK provides a report of its conclusions and recommendations to the BMI, which then determines to what extent they will be passed on to the Licensing Authority as directives:

\subsection{RADIATION PROTECTION COMMISSION (SSK)}

The BMI turns to the Strahlenschutz Kommission (SSK) for consultation in matters of radiation protection in the same manner as the RSK was consulted about nuclear safety. The SSK is organized in a similar fashion to, the RSK, with a Secretariat located at the GRS offices in Cologne.

The Radiation Protection Ordinance described in Section 4.3 is generic and requires interpretation as to technical implementation. The SSK has issued guidance on these matters. It should be made clear that the States set discharge limits for their geographical areas. Although the SSK may be consulted, these limits are not completely equivalent on a national level. Site screening requirements have been established by the Länderausschuss.

\subsection{NUCLEAR STANDARDS COMMISSION (KTA)}

The Kerntechnisher Ausschuss (KTA) was created in 1972 by the Federal Government. The KTA's purpose is to establish nuclear safety standards. Standards issued by the KTA reflect the consensus view of the five groups that comprise the KTA. The groups, with ten members each, are manufacturers, utilities, Licensing Authorities (including BMI), technical experts (GRS, TÜ's), and miscellaneous nuclear interests (such as BMFT). The fifty-member KTA is governed by a board with one member from each of the first four groups. 


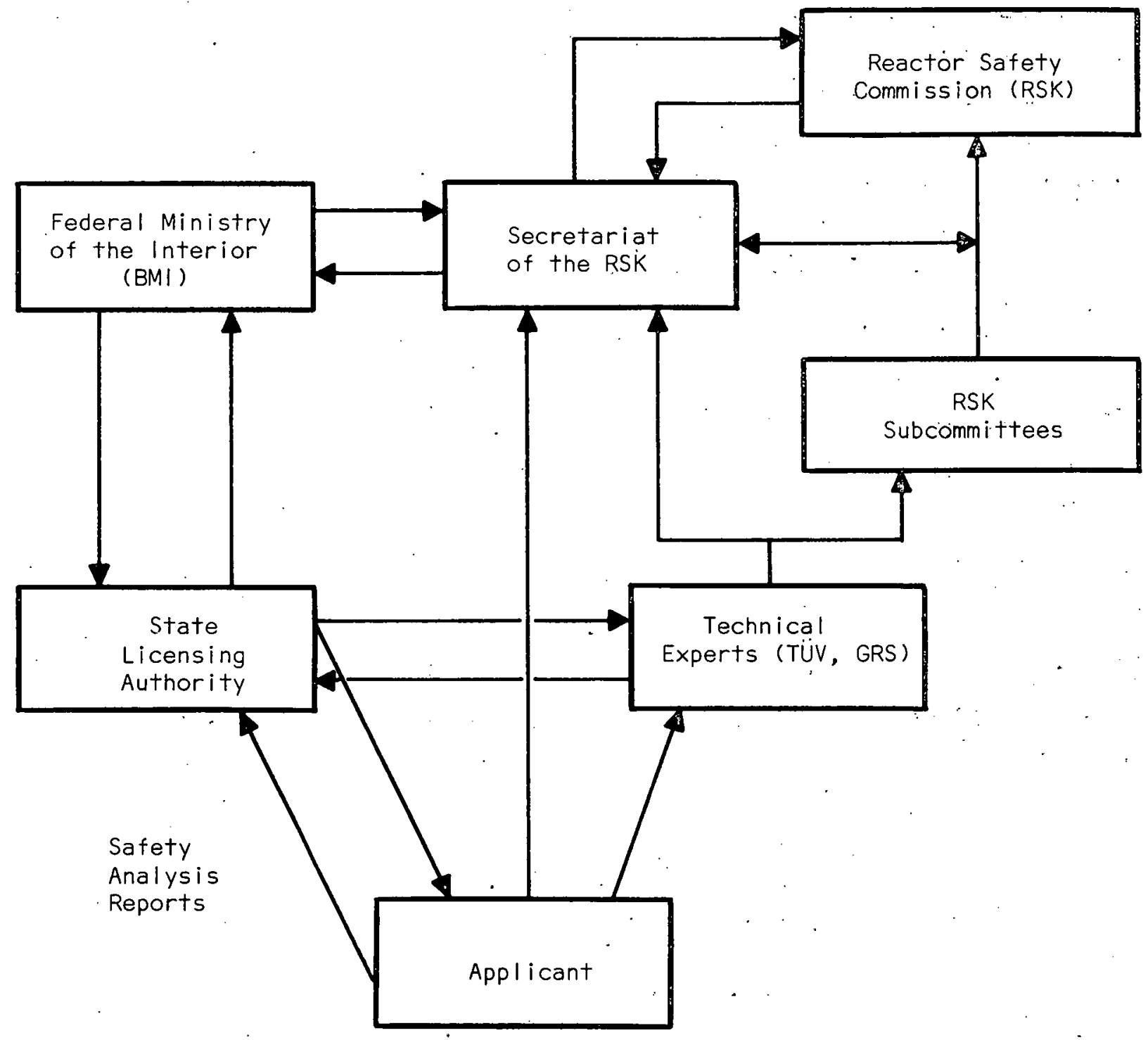

Figure 2-8. RSK Perspective of the Licensing Process 
The routine business of the KTA is conducted by the Geschaftestelle (Secretariat) whose manager, the Executive Director of the Commission, is responsible directly to the board of the KTA. The Secretariat (shown in Figure 2-9) is located at the GRS offices in Cologne, but is not part of the GRS. The activities of the Secretariat are financed by: the BMI, $28 \%$; the Association of German Electricity Suppliers (VdEW), $28 \%$; the Central Association of Electrotechnical Indusțries (ZVEI), 28\%; and the VdTüv, $16 \%$. The responsibilities of the KTA Secretariat are listed below: 8

- To conduct the business of the KTA and to carry out the general administrative activities connected with it and particularly to prepare the KTA meetings.

- To provide managerial and technical assistance to the SubCommittees (SC) of the KTA. Special importance is given to the preparation of proposals for new standards by the Program Subcommittee.

- To follow up and to assist in the preparation of individual safety guides by the various working groups.

- To create and maintain contacts with other rule-making organizations.

- To evaluate the experience gained in German 1icensing procedures.

- To collect relevant. laws, regulations, guidelines, and standards -- German, foreign and international.

- To document the rule-making process of the various projects.

- To assist BMI in its participation in the development of IAEA Standards.

The Subcommittees (SC's) shown on Figure 2-9 play an important role in the preparation of KTA Standards. The Program SC attempts to identify the need for new standards and makes appropriate recommendations to the KTA. Although the KTA approves the preparation process for new standards, the actual drafting is performed by outside organizations in the form of 


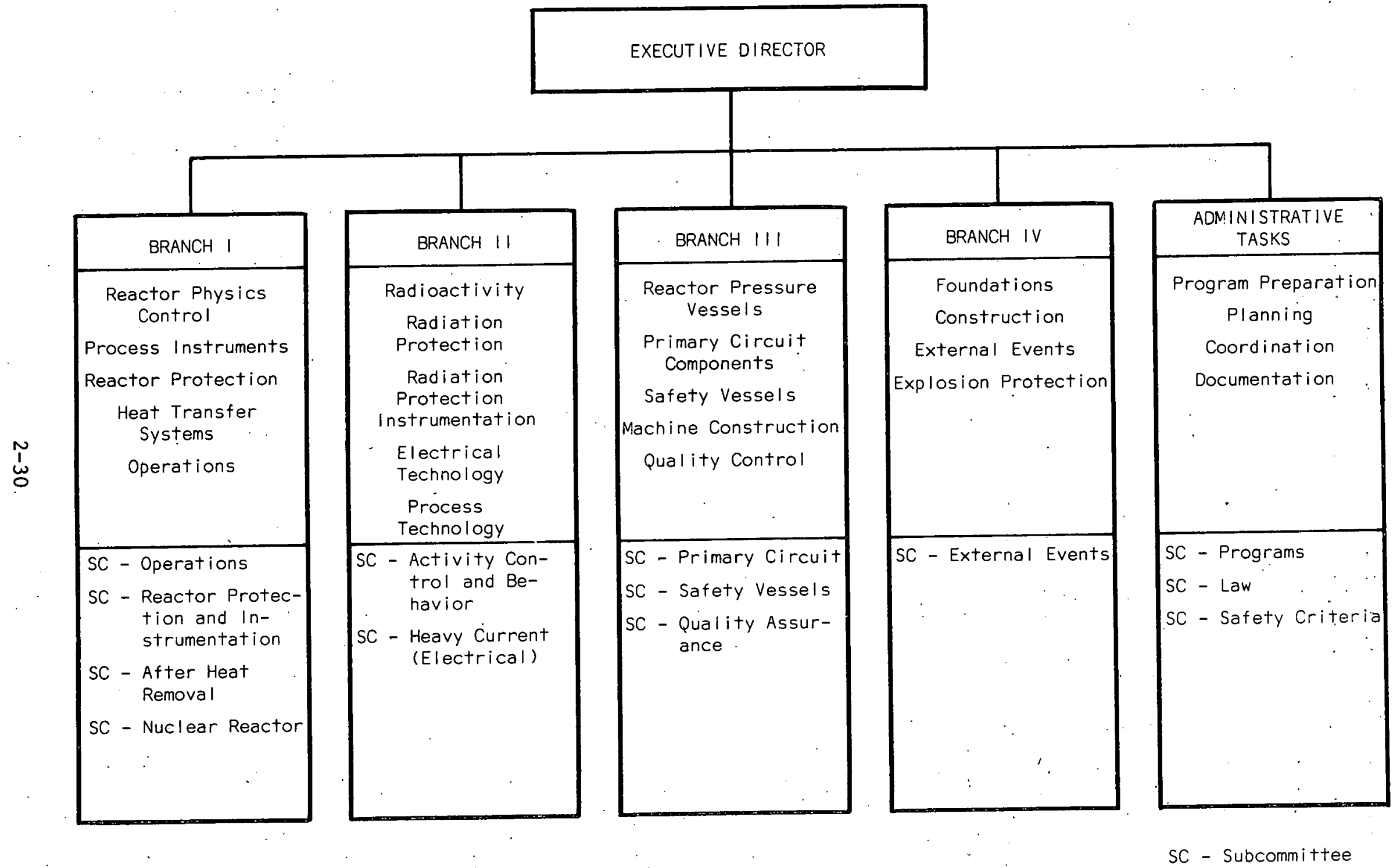

Figure 2-9. Organization of the KTA Secretariat 
Ad-Hoc working groups. The typical flow path for the preparation of a standard is shown in Figure 1-10. A more detailed description may be found in Reference 11. A. 5/6 approval majority is required at each step. After a three-month period the draft is reviewed in light of comments received. Final standards approved by the KTA are published by the BMI and are incorporated into the licensing process as technical bases. Issuance by BMI precludes the need for separate endorsement of a standard in the way the NRC in America endorses and alters standards in Regulatory Guides. The standards themselves are discussed in Section 4.7 .

Coordination exists between the KTA and the Deutches Institut für Normung (DIN or German Institute for Standardization). As a general rule, KTA is responsible, for the issuance of nuclear safety standards, while DIN is responsible for non-nuclear standards and non-safety nuclear standards.' In many cases the KTA standards build on DIN standards and simply reference the appropriate document. The DIN also acts as the German representative to the International Standards Organization (ISO).

The external working groups that normally prepare the draft KTA standards are obtained by utilizing a variety of sources. Sponsoring organizations used include the various TÜ's, the VdTÜV, the GRS, industrial companies ( $K W U, B B C$ ), utilities, etc. The most commonly used group is a subcommittee of the DIN that is contracted by the KTA called the Normenausschuss Kerntechnik (NKe or Standards Committee for Nuclear Technology). Reference 1.1 provides a detailed breakdown of sponsors and working group chairmen. 


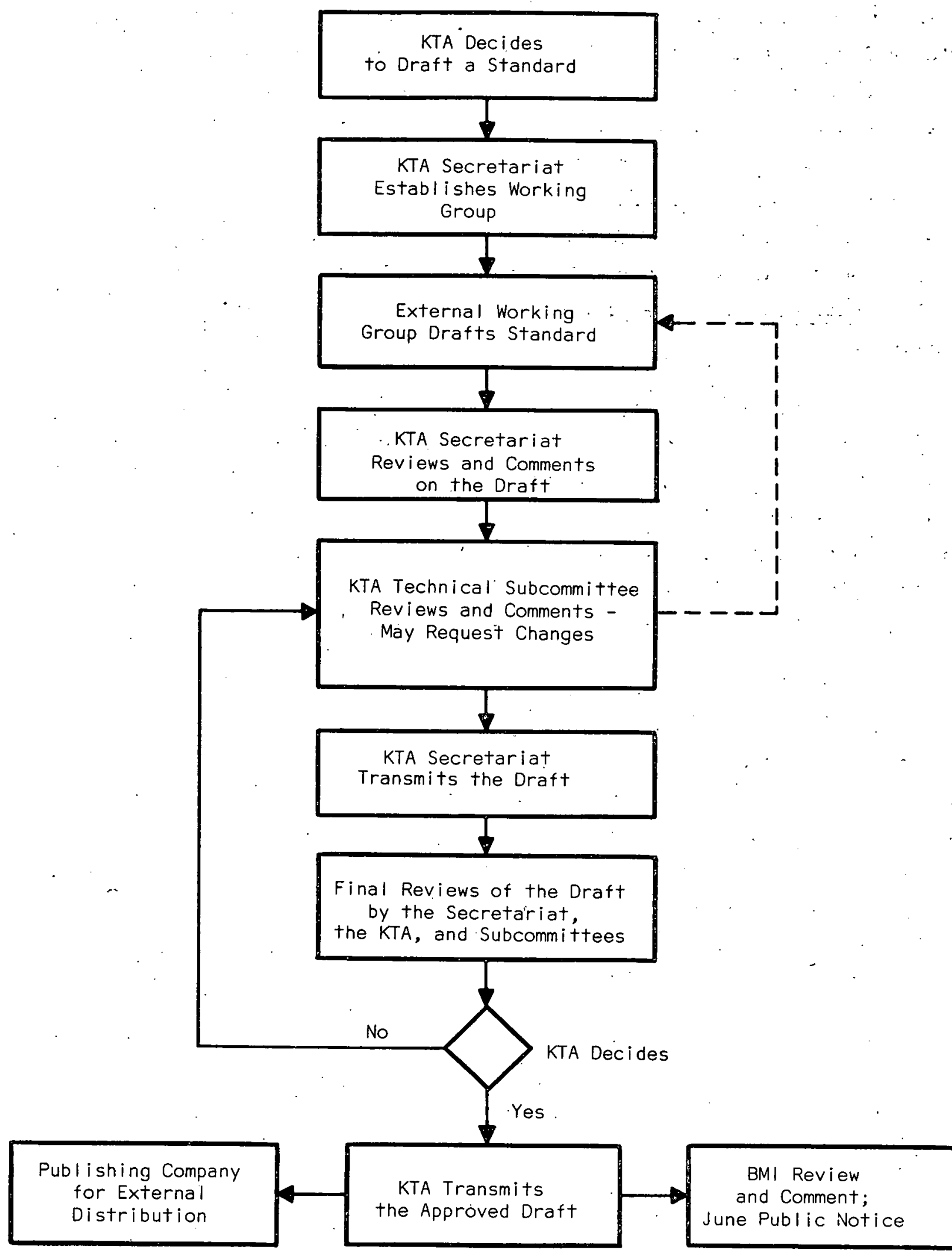

Figure 2-10. Flow Scheme for Preparation of KTA Standards 


\section{SECTION 3}

LICENSING PROCEDURES IN THE FRG

\subsection{SUMMARY DESCRIPTION}

Unlike the licensing procedure in the United States, which is based on a two-step process, the German procedure consists of a serfes of partial licenses. Each partial license is unique and deals with a specific aspect of the plant.

There are some fundamental reasons for this approach. Most important1y, when the Supreme Licensing Authority makes a ruling, it is essentially a final decision. Should the Authority change its position and later request backfitting, Section 18 of the Atomic Law requires financial compensation to the plant owner. However, if the present status of the plant is a "significant" hazard to the public, then Section 17 requires the State to revoke the license. Section 18 does not specify compensation for license revocation: Clearly the Licensing Authority would normally not want to make preliminary rulings as done in the U.S. Another problem associated with this situation is the lack of detailed technical information early in the design phase needed by the Licensing Authority in order to make a ruling. Finally, the German Atomic Law specifies that the most recent scientific knowledge and technology be used. The long construction time for a plant is sufficient for the technology to change. The later part-license proceedings can figure in changes in technology on those aspects of the plant that are being licensed (not other aspects previously licensed, however). In summary, the licensing of a nuclear facility is broken up into a series of partial licenses that allows consideration of the latest technology, permits final approval at each stage of construction based upon solid design information, and keeps the licensing activities at a relatively constant level during the lengthy construction period. Detailed instructions are provided in the Nuclear Licensing Ordinance (see Section 4.3). 
During any given partial-license proceeding, the licensee submits its application to the Supreme Licensing Authority of the appropriate state. The handling of that application was described briefly in Section 2.1. The next section will describe in detail the procedure for the first partiallicense proceeding.

\subsection{FIRST PARTIAL-LICENSE PROCEEDING}

The application and proceeding for the first partial license (PL) are particularly important since the first PL deals with obtaining approval for the site and the overall concept. The first PL also frequently includes a request for partial erection of certain buildings. Figure 3-1 graphically displays the conduct of a typical PL proceeding. (3)

The application for a license is accompanied by documents that will allow proper examination by the Supreme Licensing Authority, BMI, and the techinical experts. The first PL application includes information as summarized below: (4)

- Site Description

- location plan showing the boundaries of the nuclear power plant site

- cartographic representation of the site surroundings

- nature of soil

- ground water conditions

- flood hazards

- earthquake and mining damage hazard.

- population density in sectors (preferably $30^{\circ}$ sectors subdivided into zones). If the local population density in any one given sector is more than three times the average population density, separate plot plans of such densely populated areas have to be submitted, quoting the total number of persons concerned (name of place and number of inhabitants)

- pastures and other agricultural areas

- wildlife reservations 


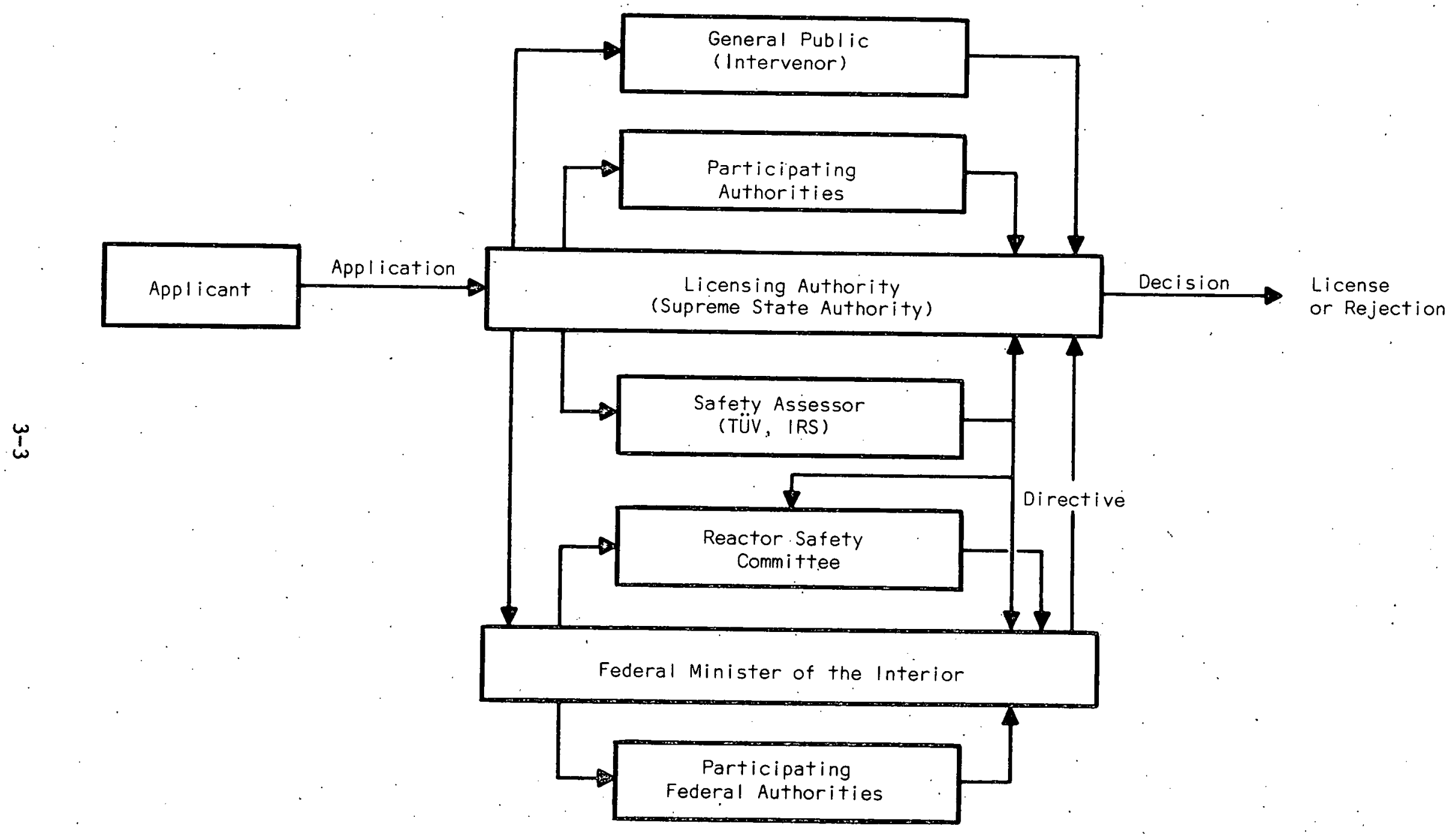

Figure 3-1. Partial License Procedure 
- facilities exposed to hazards (e.g., photographic material manufacturing plants) or constituting hazards (e.g., highpressure gas tanks, ammunition depots)

- drinking water supply facilities

- surface waterways (rivers, lakes, etc.)

- airports and air routes including mean air traffic density

- Meteorological Information

- mean annual frequency of wind directions according to a (preferably 12-point) wind rose, and of relevant wind velocities

- values of:

mean annual amount of precipitation, mean monthly amount of precipitation, mean daily amount of precipitation, al1 recorded over several years (quote number of years)

- mean annual frequency of inversion layers whose lower boundary is less than $300 \mathrm{~m}$ from the ground

- Plant Description

- purpose, location, number, dimenșions, and layout of the several buildings

- kind, purpose, design data, established minimum requirements and/or guaranteed values of the individual systems and components and the relevant service buildings insofar as these exercise an influence upon nuclear safety or are of importance for one of the other formal licensing procedures

- mode of operation

- origin, handling, and discharge of gaseous, liquid, and solid nuclear material

- cooling water requirements and cooling water intake and discharge

- Plant Technical Data

- ground plans, elevations, and views of buildings and rooms including dimensions and purposes

- heat or energy flow charts with indication of the components concerned 
- system flow charts of each medium (primary coolant, secondary coolant, tertiary coolant, emergency coolant, gas or waste gas, compressed air, room air, etc.) with indication of the com-.. ponents concerned

- system flow charts of solid, liquid, and gaseous nuclear material with indication of the components concerned

- block diagrams of power supply and emergency power supply and distribution systems

- schematic sections explaining the design of important units such as reactor pressure vessel with internals, fuel elements, control or shutdown rods with drives, primary coolant pumps or circulators, heat exchangers for primary coolants, containment refuelling equipment

- table of all systems, components, and parts quoting design data and guaranteed values or admissable maximum limits if already established

- Accident Analysis - General Safety Concept and Most Significant Accidents

- cause

- transient analysis

- effects (offsite consequences)

- assumptions and initial conditions

- calculational methods

- input data and calculated results

As in the United States, the applicant is allowed to submit proprietary data as separate documents. When the Licensing Authority accepts the application as complete, it contracts technicai experts to conduct the expert evaluation, consults other affected state authorities, and involves the BMI. While the Licensing Authority is conducting its review, the BMI coordinates reviews at the Federal level by other Federal Ministries and the RSK. 
The Nuclear Installations Ordinance explicitly requires the: Licensing Authority to make a public announcement of the proposed PL by publication. in a local newspaper of "substantial circulation" and in the Federal Register. The applicant is required to prepare a separate document on the PL topic of a quality sufficient for public scrutiny. Third parties (intervenors) may object to the Licensing Authority, who must consider them. A public hearing is conducted by the Licensing Authority.

Prior to a Licensing Authority ruling it receives the considered opinion of its contracted technical experts, other affected authorities, and objections by intervenors. The Authority then makes its decision on the application independently. If BMI (and its experts) issues directives to the Authority for the application, they are binding and must be implemented.

Once the ruling has been made, parties making objections, including the applicant, can take action against the Licensing Authority in Administrative Court. This procedure is different from that of the United States, since the Authority is taken to court in Germany and not the utility. In fact the utility may take the authority to court if it does not like the terms of the PL (the utility VEW actually intervened against the seismic design criteria imposed on the THTR plant).

The receipt of the first PL allows the utility to begin work on foundations and lower structures as specified in the particular application. Even more important, the first PL provides formal approval of the site and the design concept, which allows the utility to proceed to the next PL with some confidence that the rules will not be changed on what has already been approved (unlike the situation in the U.S.).

There are provistonal decisions allowed by Section $7 \mathrm{a}$ of the Atomic Law. These decisions resemble policy statements, since they answer questions of interest to the licensee. These decisions are, however, final and remain in force for up to four years. Typical examples apply to the site: and the concept. A positive provisional decision implies that the Licensing Authority cannot reject the site or the basic concept during the ensuing proceeding. Needless to say, rejection of a design later found to be unsafe would in fact occur. 


\subsection{SUPPLEMENTAL PARTIAL LICENSES}

The procedure described above in Section 3.2 is repeated each time a succeeding PL application is received. These follow-on PL's relate to successive stages of construction for the plant as the design analysis is completed. Intervention during supplementary PL proceedings can only relate to the subject at hand. This is important, since it means that previous PL's are not open targets for re-intervention. Figure 3-2 graphically displays the time behavior of the overall licensing process.

Eventually the Licensee applies for an operating license. Technical Specifications had been approved for each aspect of the plant during the preceding PL approvals. When applying for an operating license, the following general documents are required:

- Final safety analysis

- Program for initial fuel loading and comissioning the plant

- Operational organization

- Protection and safety rules

- In-service inspection prögram..

$\because$ Physical security precautions

Prior to issuance of the operating license the procedure described above is repeated. The license constraints (emergency planning, radiation protection specifications, and operating requirements) for the,plant are included in the plant "Betriebshandbuch" (Operations Handbook), a document similar to the Plant Technical Specifications in the United States. 


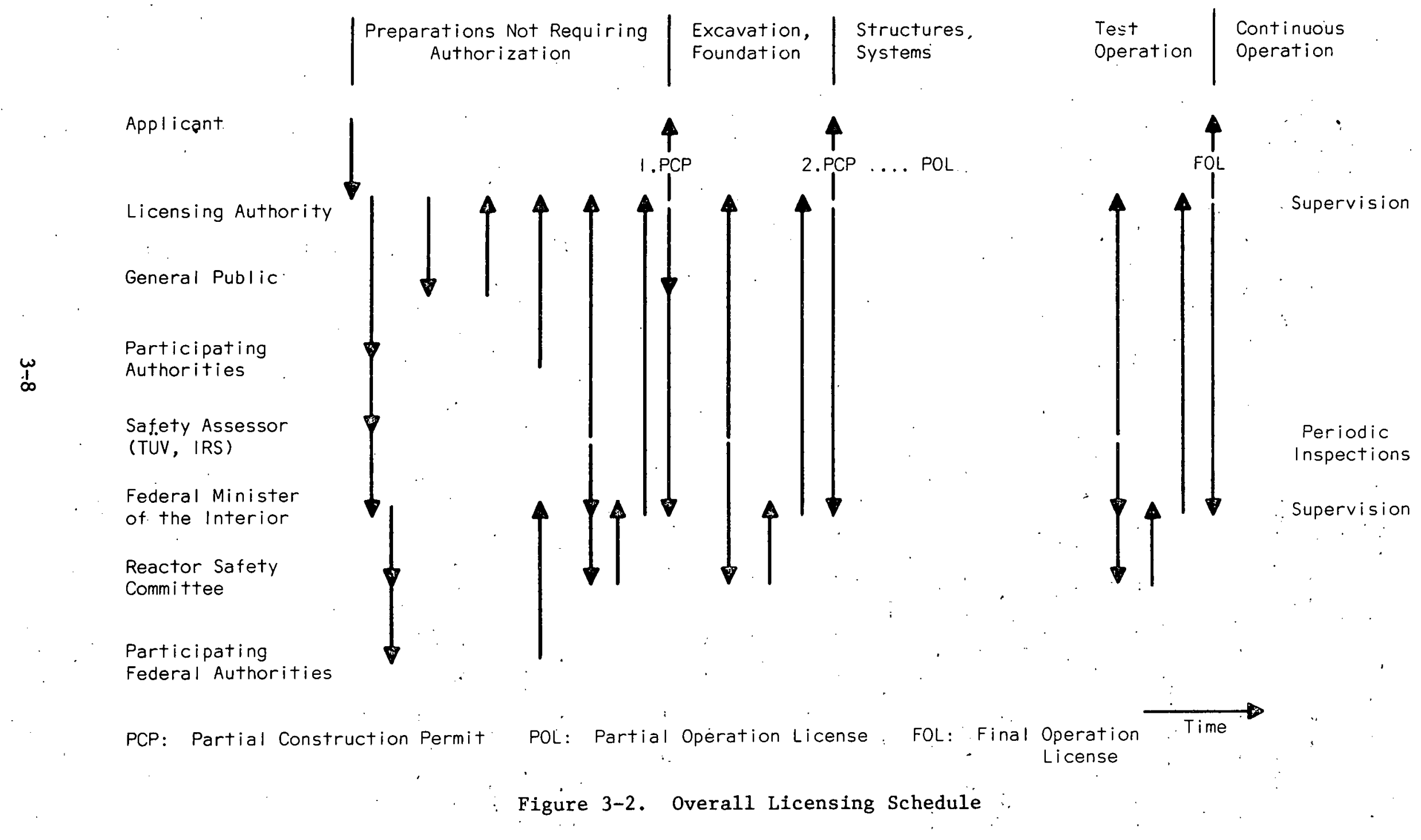


SECTION 4

GENERAL DESCRIPTION OF GERMAN NUCLEAR CRITERIA

\subsection{ORGANIZATION AND RELATIONSHIPS}

As discussed in Section 1.3, the regulations and guides in the United States are essentially of four types: Federal laws, federally issued nonbinding guidelines, industry consensus standards, and state or federally sanctioned codes developed by industry (e.g., ASME Boiler and Pressure Vesse1 Code).

The Iicensing framework in Germany has given rise to an organization of codes, standards, and regulations that is somewhat different. There are two broad classes of criteria: Rules of Law, which are legally binding, and Rules of Technology, which are not legally binding. As will be discussed in the following sections, the Rules of Law are generally issued by the Federal Government, while the Rules of Technology are issued by a spectrum of groups involved in the nuclear licensing process. There are some laws issued by the various states in areas where they have cognizance, such as water usage criteria and building codes. Figure 4-1 shows an overall view of the German 1 icensing criteria. It will be demonstrated that the Rules of Technology have significant force even though not truly legal requirements.

\subsection{THE GERMAN ATOMIC LAW}

The German constitution was amended in 1959 to add the Atomic Law which became the cornerstone of all German nuclear regulation. Somewhat similar to the American Atomic Energy Act, the Atomic Law provides a legal basis for the peaceful uses of nuclear energy. The Atomic Law includes guidance in such areas as: import-export, transportation, storage and possession of nuclear fuel; licensing for the storage of nuclear fuel; licensing of stationary plants for the production, utilization, and reprocessing of nuclear fuel; provisional licensing decisions; intervention; etc. 


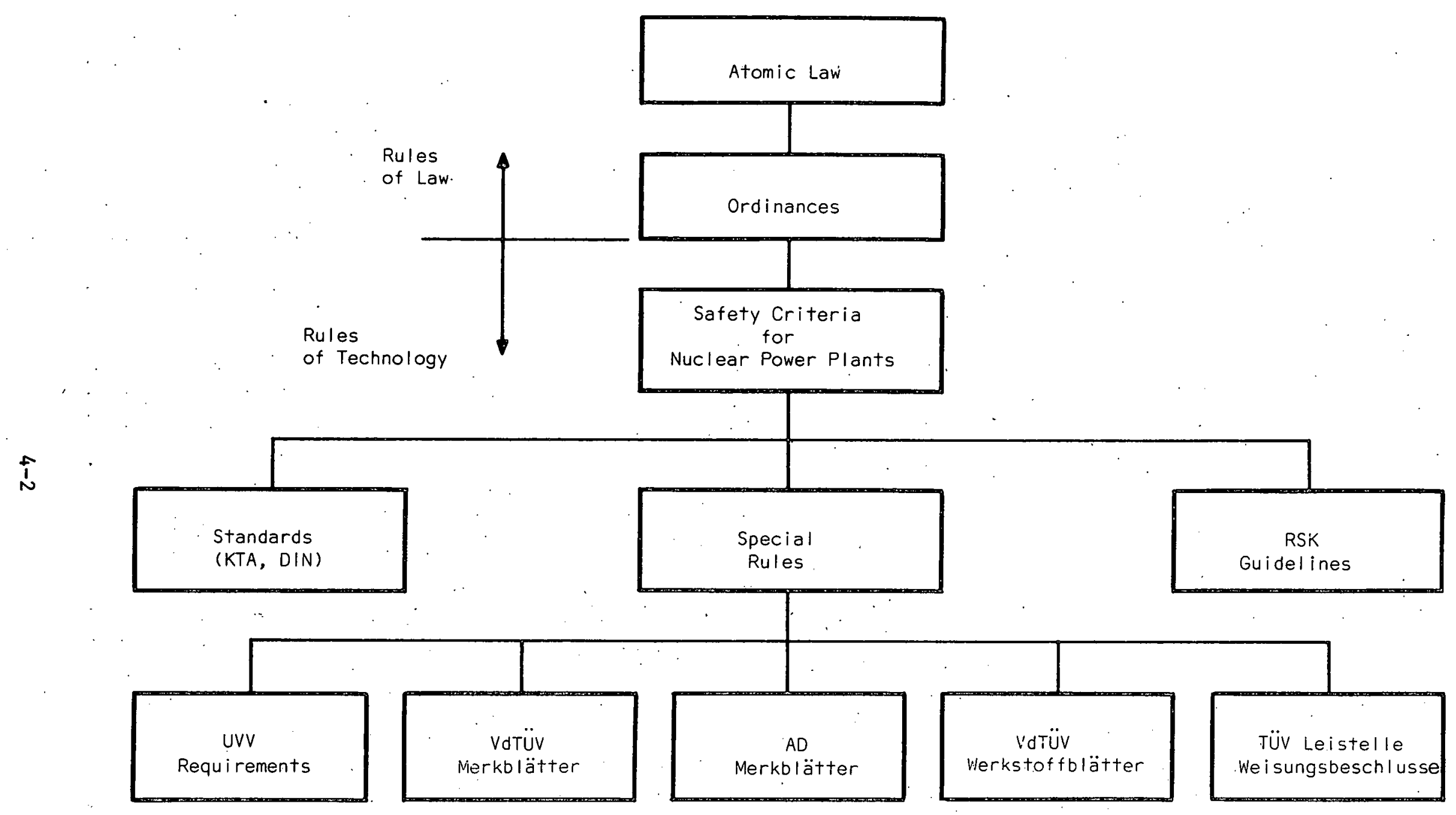

Figure 4-1. German Regulations and Guidelines 
The Law requires licensing of activities utilizing fissionable materials specifically, import and export, transportation, handling, and construction and operation of nuclear installations. Section 7 of the Law specifies that: ${ }^{(3)}$

"... any person who conducts, operates, or otherwise holds any stationary installation for the production or fission of nuclear fuel, or for the reprocessing of irradiated nuclear fuel, or who essentially alters such installation or its operation, sha11 require a license. Therefore, granting of such a license is subject to meeting various licensing prerequisites which aim at the protection of employees, unrelated third persons and the general public."

Section 7 of the Law assigns responsibilities to the Federal, State; regional, or other authorities for their participation. in the licensing process, and requires that licenses can only be granted: (3)

- Where there are no known facts giving rise to any doubts as to the reliability of the applicant and the persons responsible for the construction, management, and supervision of the operation of the installation, and where said persons responsible for the construction, management, and supervision possess the required expert knowledge; .

- Where every necessary precaution has been taken in the light of existing scientific knowledge and technology to prevent damage resulting from the construction and operation of the installation;

- Where the necessary financial security has been provided to cover al1 legal liability to pay compensation for damage;

- Where all necessary protection is provided against interference or other intervention by third persons (sabotage, external events); and

- Where there are no overriding public interests against the siting of the installation, especially regarding non-contamination of water, air, and soil. 
The second item above is very important to the present state of nuclear licensing in Germany. The requirement for use of the best existing safety technology is part of a law, and the technical interpretation is performed by the Licensing Authorities using their best judgments. However, these judgments are open to judicial review. A current controversy.stems from the planned BASF nuclear facility (PWR) for process steam at a chemical plant. The urban siting caused the plant to be designed with burst protection for the entire primary loop (i.e., prestressed concrete vessels around the reactor vessel, steam generators, and piping). The plans for the plant were subsequently dropped. However, recently a State administrative court ruled that burst protection was the best existing technology and should be imposed on all plants, whether urban or rural. (Note that this is a legal interpretation and not a technical statement.) In a reverse decision, a court in another state ruled that. burst protection is not required, based upon a statement by the RSK . experts. The outcome of this controversey is not yet clear. The BMI is working to include technical requirements in an ordinance, thus making the more specific guidance binding on all parties, including courts.

The Atomic Law includes general guidance on the subject of financial protection for nuclear facilities. The Federal Republic has ratified the Paris Convention on Third Party Liability in the Field of Nuclear Energy and the Brussels Supplementary Convention. The current limit on liability is 1 billion DM ( $\$ 430$ million). There are different limits for damage from facilities located outside of Germany. If a foreign facility causes damage in Germany, the accident will be covered as if German in origin (i.e.,1 billion DM protection). The division between public indemnification and private insurance is different from that in the U.S. but is not of interest to this study.

A final aspect of the Atomic Law that should be mentioned is the inclusion of a catalogue of penalties and fines. These provisions ensure enforcement of the intent of the Law.

\subsection{ORDINANCES}

Within the body of ordinances included in the German legal framework are the Nuclear Ordinances, which are binding upon the Federal and State 
Authorities, in addition to private organizations. There are presently three ordinances that affect the nuclear licensing procedure:

- Atomrechtliche Verfahrenssverordnung-AtVfV (Nuclear Licensing Ordinance)

- Strahlenschutzverordnung-Strl Sch V (Radiation Protection Ordinance

- Atomrechtliche Deckungsvorsorge VerordnungAtDechV (Third Party Indemnification Ordinance)

There are also two ordinances in draft status: Qualification of Operating Personnel and Qualifications and Organization of Non-Staff Experts (1.e., TUV, GRS, etc.). The Nuclear Licensing Ordinance specifies the procedure for licensing proceedings, the types of submittals required, public inspection of documents, public hearing conduct, procedural conditions for partial licenses, etc. The recently issued (18 February 1977) Radiation Protection Ordinance specifies the use of the "As Low as Practicable" concept for control of radiation exposures, even if those exposures are less than allowable limits. The Ordinance reduced post-accident dose limits to 5 rem whole body and 15 rem thyroid (lower than the U.S. requirements of 25 and $300 \mathrm{rem}$, respectively) and reduced the occupational exposure limits from 12 rem per year to 5 rem per year. The Ordinance. also provided more detailed guidance on control of radiation zones and. effluent controls.

\subsection{SAFETY CRITERIA FOR NUCLEAR POWER PLANTS}

The first level of the non-binding Rules of Technology are the Sicherheitskiterien für Kernkraftwerke, first issued on 25 June 1974. In scope and depth these criteria are similar to the U.S. General Design Criteria of 10CFR50 Appendix A. The U.S. criteria are, however, rules of law.

The German Safety Criteria were drafted by people from BMI, the BMFT, the GRS, and a special group from the KTA during the period 1972 to 1974. After completion of the draft, comments were solicited from all affected groups in the licensing procedure. The comments were incorporated as practicable, and finally the criteria were approved by the Landerausschuss and issued by the BMI. The criteria were written for water-cooled reactors, but other reactor types must meet their intent. 
The Technical Appendix to this report provides a detailed analysis of the Criteria. The following is a list of the topics of the criteria:

-Quality Assurance

-Testability

-Radiation Exposure of the Environment

-Radiation Exposure in the Plant

-Arrangement of the Work Area, Work Cycle, Work Environment

-Effects from External Events

-Protection Against Fire and Explosion

-Access Control, off-Limit Areas

-Escape Routes and Means of Communication

-Decommissioning of Nuclear Power Plants

-Reactor Design

-Inherent Safety

-Reactor Pressure Vesse1 Internals

-Reactor Coolant Pressure Boundary

-Residual Heat Removal During Specified Normal Operation

-Residual Heat Removal After Loss-of-Coolant Accidents

-Monitoring and Alarm Systems

-Incident Instrumentation

-Equipment for Control and Shutdown of the Nuclear Reactor

-Control Room and Auxiliary Control Installations

-Reactor Protection System

-Emergency Power Supply

-Containment of the Nuclear Reactor

-Design Bases for the Containment

-Leakage Tests of the Containment Vessel

-Containment Vessel Penetrations

-Heat Removal from the Containment

-Ventilation and Air Filtration Systems

-Radiation Protection Monitoring

-Monitoring and Activity of Exhaust Air and Waste Water

-Environment Monitoring

-Handling and Storage of Nuclear Fuel and Other Radioactive Substances 


\subsection{RSK GUIDELINES}

As discussed earlier, the Reactor Safety Commission performs technical reviews of license applications for the BMI. On 24 April 1974 the RSK Guidelines for Pressurized Water Reactors were issued. These Guidelines were actually prepared by the RSK and its subcomittees, a1though external comments were received. The Guidelines are more detailed than the broader guidance of the Safety Criteria and are given significant force since the RSK specifles that the Guidelines will form the basis of their technical reviews. The Guidelines are consistent with the provisions of the criteria and today are used by all the participants in the nuclear licensing process. These Guidelines were written for PWR's; however, other reactor types have to meet their intent.

The Appendix to this report analyzes the RSK Guidelines; however, below is a general list of the topics covered in them:

-Quality Assurance

-Radiation Exposure Control

- External Hazards

-Reactor Core

-Reactor Cooling Systems

- Instrumentation, Control, and Shutdown

-Reactor Protection Systems

-Emergency, Power

-Containment

-Ventilation Systems

-Monitoring and Radioactive Materials

-Handling and Storage of Nuclear Fuels and other Radioactive Materials

\subsection{CONSENSUS STANDARDS}

The KTA prepares consensus standards as discussed in Section 2.10. Many standards are in various stages of development. Below are 11sted those standards actually issued, at least as first drafts, as of March 1977.

KTA 1501 Stationary System for Monitoring Dose Rates Within Nuclear Power Plants Design of Nuclear Power Plants Against Seismic Events 


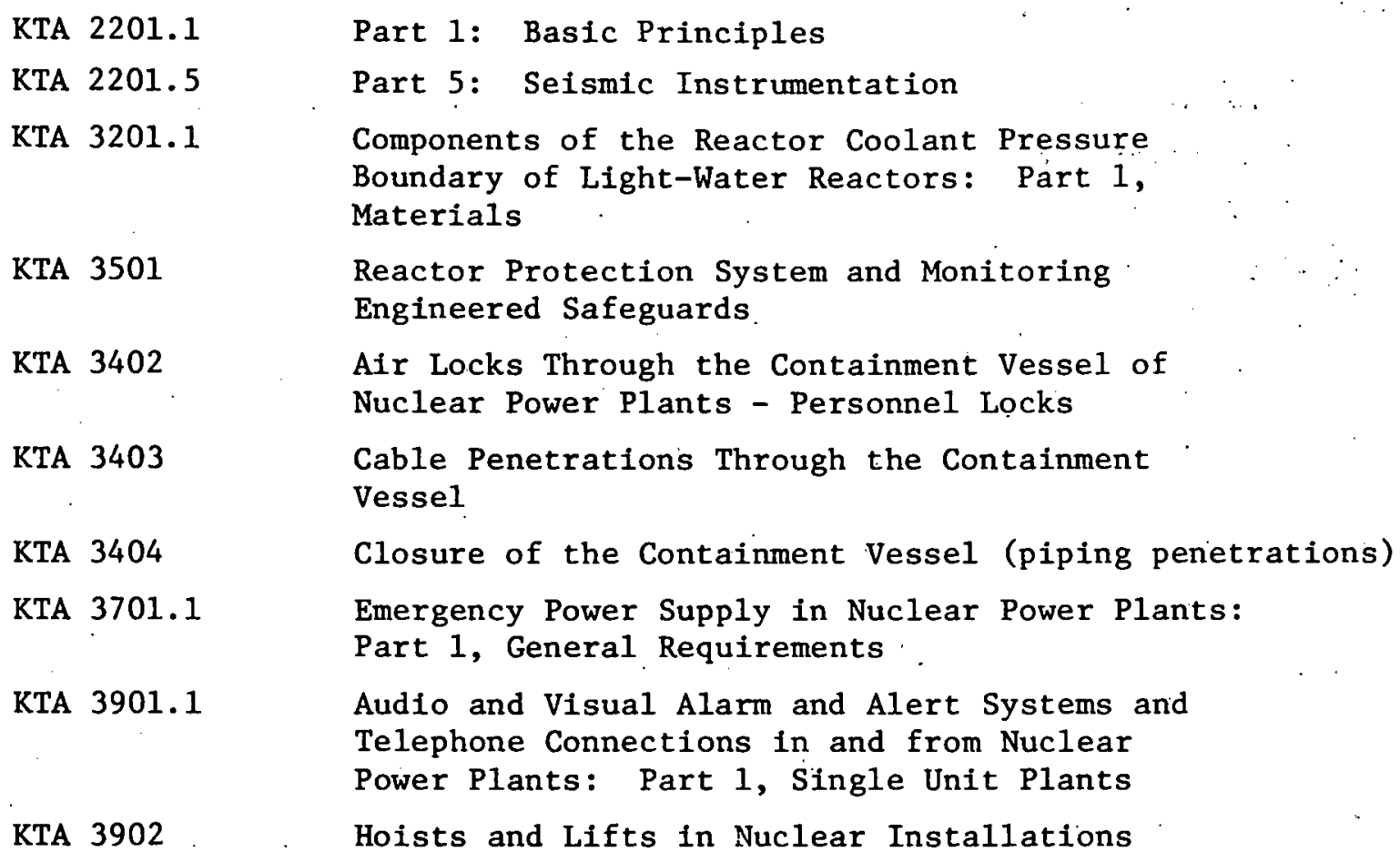

\subsection{OTHER REQUIREMENTS}

A large body of technical criteria used in the nuclear licensing process has not been described above. These criteria include non-nuclear standards, interpretations of the Rules of Law and Rules of Technology, materials specifications, and other detailed technical instructions. For convenience these other criteria are called herein "Special Rules." The most important Special Rules are shown on Figure $4-1$. Detailed analysis of these requirements has not been included in this report.

In the FRG there exist a number of "Societies for the Protection of Industrial Workers" that represent the various workers (from engineers to miners) in relations with corporate managements. These Societies really do not have an equivalent in the U.S. Through the years these societies have developed Rules of Technology called the Unfallverhütungsvorschriften or, more commonly, the UVV (Rules for the Prevention of Accidents to Man). The UVV Requirements include such topics as creep measurement, boiler in-.. spection, heat treatment of welded seams, and testing of conventional equipment. Enforcement is accomplished by the use of inspectors (similar to OSHA enforcement in the U.S.). 
The VdTÜV issues a series of "Reference Sheets" that clarify and detail the UVV Requirements. These Reference Sheets are called the VdTüV Merkblätter, and in some situations they can be issued to correct the UVV Requirements until the latter document can be revised. This activity is similar to ASME Code Cases in the U.S.

The VdTÜV, in cooperation with a group of other organizations, issues different Reference Sheets called the Arbeitsgemeinschaft Druckbehalter (Working Association for Pressure Vessels) Merkblätter; or, more simply, the $\mathrm{AD}$-Merklatter deals with conventional pressure vessels in such areas as materials, welding, inspection, manufacturing, etc. They are, therefore, not unlike the ASME Code. The main topics are listed below:

\begin{tabular}{cl} 
Section & Topic \\
\hline G & General Information \\
W & Materials Specification \\
RW & Reactor Pressure Vessel Materials \\
N & Non-Metallic Materials \\
H & Manufacturing \\
B & Calculations \\
A-1 & Burst Protection \\
A-2 & Safety Valves
\end{tabular}

A third set of Reference Sheets is issued by the VdTü to clarify, detail, and interpret certain AD-Merkbläter materials criteria. These are called the VdTüv Werkstoffblätter (Materials Reference Sheets).

The role of the VdTÜ in ensuring consistent expert evaluations in the field of nuclear technology by the various member Tư's is being carried out by a special group of the VdTUV. "This group is called the TUV-Leitstelle Kerntechnik bei der VdTUV (Special TUV Nuclear Technology Office of the VdTUV or, more commonly, the Tü-Leitstelle. The TÜV-Leitstelle has been in operation for about two years and is composed of known experts in special areas from the member TUV's and the GRS. The purpose of the TÜV-Leitstelle is to resolve differences in interpretation within the TUV's and the GRS. Pronouncements issued by the TÜV-Leitstelle are called Weisungsbeschlusse, or Special Obligations. There are currently. about seventeen of these documents with more in varlous stages of preparation. Weisungsbeschlusse, are only issued in areas where the KTA has not issued standards. 


\section{SECTION 5}

\section{GAS REACTOR LICENSING}

\subsection{BACKGROUND}

The descriptions of the German Nuclear Licensing Framework (Section 2) and the FRG Licensing Procedure (Section 3) would be correct regardless of the reactor type being licensed. The criteria of Section 4, however, are really only strictly applicable to the licensing of light water reactors (LWR's). Similarly, the brief description of U.S. criteria in Section 1.3 was directed at the developed body of criteria for U.S. 1ight water reactors.

The focus of this study has been to document the procedures and criteria for FRG nuclear licensing as part of an overall General Electric Company assessment of a proposed International Cooperative Gas Reactor Program. It is, therefore, necessary to identify the current status (and previous experience) of gas-cooled reactor licensing in both the U.S. and the FRG.

Commercial gas reactor licensing in the U.S. started with Peach Bottom Unit No. 1, which began commercial operation in 1967. The Peach Bottom plant ( $40 \mathrm{MW}_{\mathrm{e}}$ ) was helium-cooled and graphite-moderated. The configuration was fundamentally different from that of the next generation, the High Temperature Gas-Cóoled Reactor (HTGR), which utilizes prismatictype fuel elements). The Fort St. Vrain HTGR is a $330 \mathrm{MW}$ plant owned by the Public Service Company of Colorado and designed by the General Atomic Company. The construction permit of Fort St. Vrain was granted in September 1968, and construction was essentially complete in 1977.

During the pertod 1973-1975 a number of large-scale prismatic HTGR's were ordered by U.S. utilities for operation in the 1980's. For a number of reasons this attempt at commercialization failed; however, several of 
the plants were taken through a significant portion of the licensing process prior to cancellation.

The experience of gas-cooled reactors in the FRG was not unlike that in the U.S. The Arbeitsgemeinschaft Versuchsreaktor (AVR) is a small pebble bed reactor (PBR) rated at $46 \mathrm{MW}_{t}$. It uses ball-type fuel with online refueling. Like Peach Bottom, the AVR began operation in 1967. Construction on the next generation PBR began in 1971. The Thorium High-Temperature Reactor (THTR) is rated at $300 \mathrm{MW}$ and is presently scheduled for commertcal operation in 1981. During the period 1973-1975 the THTR designer HRB (owned 45\% by the U.S. company General Atomic) offered prismatic HTGR's in Germany due to the apparent success in the U.S. Licensing reviews of the HTGR were performed by the participants in the German nuclear licensing process (notably the TUV in Nordrhein-Westfalen).

\section{$5: 2$ CURRENT STATUS}

Gas reactor licensing activities are presently at a low level both in the U.S. and in FRG. Fort St. Vrain and THTR are still in the licensing process, although the U.S. plant is essentially complete, while THTR has a number of partial licenses yet to go. The U.S. emphasis on standardization of design has resulted in the issuance by the General Atomic Company of a Standard Safety Analysis Report (GASSAR) for the commercial-size HTGR. The GASSAR has been reviewed in large part by the NRC staff, and continued review will occur with low priority due to the lack of a specific license application. In Germany THTR is the only active gas reactor licensing effort in that country at the moment.

There have been some criteria issued by the U.S. Nuclear Regulatory Commission specific to gas reactors. An example is the Standard Format for Safety Analysis Reports-HTGR Edition, which will form the basis for future submittals. Some technical guidance has also been prepared. The licensing activities of 1973-1975 formed a good experience base for NRC reviews of HTGR's. In mid-1975 the Regulatory Staff performed an examination of existing criteria for applicability to HTGR's. Draft General Design Criteria for HTGR's were actually prepared but never formally implemented 
In 10CFR50; therefore, HTGR's are still required to meet the general intent of the existing criteria. The NRC also examined the applicability of the Standard Review Plans and Regulatory Guides; however, work in this area has not been continued. Finally, industry consensus standards for HTGR design and operation were begun in 1973-1975. A number were issued, at least in preliminary draft version, before the work priority was lowered.

The development of detailed criteria for gas-cooled reactors in Germany is behind that in the United States. Reactors such as THTR are required to meet the intent of the Safety Criteria for Nuclear Power Plants. The BMI is planning to draft new Safety Criteria specifically for the gascooled reactor type, but work has not yet begun. Since development of LWR codes and standards has the highest priority, there has been little work in the gas reactor area.

In summary, then, codification of gas reactor licensing criteria is significantly behind that for light water reactors. Criteria in the U.S. for gas reactors are more extensive than those in Germany. Finally, both countries have a history of gas reactor licensing based on a small prototype built in the early $1960^{\prime}$ s, a prototype plant built in the early 1970's, and reviews of the prismatic HTGR during the period 1973-1977. Neither country has performed licensing activities for very-high-temperature reactors for process heat. 
SECTION 6

CONCLUSIONS

\subsection{PROCEDURAL DIFFERENCES}

The previous sections of this report have shown that the process of nuclear licensing is substantially different in the two countries. The United States process can be characterized as the centralized two-step method. The Nuclear Regulatory Commission conducts virtually all aspects of nuclear plant licensing from site approval to inspection of operating plants. The licensing procedure essentially consists of two distinct phases: application for a Construction Permit and application for an Operating License.

The process in the Federal Republic of Germany can be characterized as the exact opposite. Supervision of licensing procedures is conducted by each state in a semiautonomous manner, although the Federal Government exerts influence on the various states during the proceedings. Unlike the U.S. 1icensing supervisor (NRC), the German governmental bodies do not maintain a large in-place technical staff. Instead they make major use of outside private technical groups. As a consequence, the interpretation of technical criteria is somewhat variable. Work to ensure consistency in the conduct of nuclear licensing is progressing. The confederation nature of the German Government presents some additional problems with respect to consistency. The basic technical requirements for nuclear plants are federal; however, many other criterla (water usage, building codes, etc.) are omitted and thus are implemented by the states. This means that certain design constraints for nuclear plants are variable by state.

Procedural differences between the U.S. and Germany are therefore extensive. It is concluded, however, that such differences do not present a major impediment to an international cooperative gas reactor development 
program. Procedural differences are of primary interest during actual licensing proceedings (i.e., who gets what information at what time). The licensing of a specific plant in a specific country will be the responsibility of participants from that country. On the other hand, development of support data for licensing activities is an important part of a cooperative program. Therefore, program management should include proper planning to ensure that test data, experimental results, calculational tools, etc., are developed in such a way that they are acceptable to both countries' safety authorities. Early involvement by these safety authorities should also be anticipated. Resolution of these procedural issues will be examined further in future studies.

\subsection{TECHNICAL REQUIREMENT DIFFERENCES}

The resolution of differences in technical criteria presents a formidable task in the management of an international cooperative program. Sections 1.3 and 4 described the types of technical rules which exist in the United States and Germany, respectively. Appendix A highlights the major differences in the basic criteria. Although the detailed requirements imposed in Germany, such as the "Special Rules" of Figure 4-1, were not examined as part of the present study, meaningful conclusions can be drawn.

It is clear that the fundamental principles of nuclear safety and radiation protection are the same in both countries, i.e., defense in depth, quality assurance, ICRP exposure controls, etc. The implementation of these precepts, however, is somewhat different. In most situations it appears that nuclear safety criteria are more conservative in Germany than in the United States; for example, redundancy requirements are more severe in Germany. However, In some cases, the U.S. is more conservative: for example, the NRC requires analysis based on combined accident and seismic loads instead of the worst of the two. U.S. criteria are significantly more codified as Standard Review Plans, Regulatory Guides, etc. This developed body of nuclear safety criteria identifies assumptions, safety margins, analytical techniques, etc., to a larger extent than do existing German criteria. It is important to understand that the higher level of German conservativism cannot be directly correlated to an assumption that German reactors are safer than U.S. reactors. Appendix A should be consulted for more detailed conclusions as to technical criteria differences. 
The international program management scheme must include resolution of the different designs mandated by licensing criteria. Resolution may take the form of the most conservative design or multiple designs for various systems and components. The German Special Rules, such as the various Merkblatters, will have to be evaluated against the ASME Boiler and Pressure Vessel Code, the ASTM Standards, and other codes and standards. Plans must be developed which will allow the nuclear safety-related components and systems fabricated in one country to be accepted in the other. These problems have been encountered to some extent in other international ventures; however, a nuclear cooperative development program offers unique but not insurmountable difficulties.

Since the most likely area of cooperation may be nuclear process heat using a gas-cooled reactor, an opportunity to overcome licensing difficulties exists. Neither the U.S. nor Germany has criteria for such a plant. Early technical involvement by the safety authorities in some unified review scheme should be attempted. This approach would allow truly international nuclear criteria to be developed and potentially remove or reduce the obstacle of non-uniform technical criteria. The experience of safety authorities in nuclear process heat plants would also be increased during the period leading up to the first submittal of a specific licensing application. Therefore, the management plan should include early preparation of the draft "Nuclear Safety Criteria for Gas-Cooled Nuclear Process Heat Plants." 
SECTION 7

REFERENCES

(1) Long, J.A., "The Reactor Licensing Process: A Status Report," Nuclear Safety, Vol. 18, No. 3, May-June 1977.

(2) Minogue, R., "Nuclear Regulatory Commission Regulations and Licensing," Nuclear Power Safety, Pergamon Press Inc., 1976.

(3) Franzen, L., "Nuclear Licensing Procedure in the Federal Republic of Germany," GRS-Cologne, July 1976.

(4) "Assessors' Activities within the Scope of the Licensing Procedure under the German Atomic Energy Act from the Viewpoint of the Technical Inspectorate Associations," VdTUV, May 1971.

(5) "Authorization Procedures for Nuclear Power Stations in the German Federal Repub1ic," BMI, January 1974.

(6) "A11 About TÜV," Confederations of TÜV's (VdTUV), February 1977.

(7) Furste, W., "TÜV Functions During Operation of Nuclear Power Plants," TüV-Essen, Undated.

(8) "Reactor Safety Institute 1965-1975," IRS-Cologne, 1975.

(9) "Contribution for the Compilation of National and International Standards," Kerntechnischer Ausschus (KTA), March 1977.

(10) "HTR Licensing Procedure and Safety Philosophy in the FRG," Mr. Kellerman, Director GRS, May 1975.

(11) "Kern Technischer Ausschuss (KTA) Jahresbericht 1976," Issued by the Geschäfsstelie (Secretariat) of the KTA. 
APPENDIX A

U.S./FRG Technical Licensing Criteria

\section{A.1 INTRODUCTION}

The general character of U.S. and FRG technical licensing criteria, while leading to a similar set of performance requirements and level of safety, are distinctly dissimilar in many respects. Consequently, a comparison of technical criteria is analogous to that for licensing procedures, and it is difficult to achieve a one-to-one comparison between corresponding regulations. In general, BMI Safety Criteria for Nuclear Plants are similar to U.S. General Design Criterla (10CFR50 Appendix A), RSK Guidelines for Pressurized Water Reactors are similar to USNRC Regulatory Guldes, Nuclear Ordinances are roughly analogous to 10CFR50 technical appendices (by character, if not content), and DIN nuclear standards are similar to their ANSI counterparts. 


\section{A. 2 FUNDAMENTAL DIFFERENCES}

The most apparent difference in criteria is that a considerably greater degree of documentation exists within the U.S., both in the definition of regulations and standards and in the documented interpretation of these criteria by regulatory authorities. This documentation of regulatory positions is in the form of questions and answers on applicant dockets; Branch Technical Positions issued by NRC, and a comprehensive set of Standard Review Plans, also from NRC. Branch Technical Positions (BTP) have arisen out of concerns raised during the review of individual dockets. These positions, which are listed in Table A-1, are issued by the various technical review branches within NRC. They are intended to supply guidance on specific positions which have been raised out of negotiation with previous applicants and which would. be expected to remain in effect for future plants. Standard Review Plans (SRP) have been issued as guidance to NRC reviewers so that a uniformity and stabilization is achieved in the review from one plant to the next. These plans provide detailed guidance as to areas of review, acceptance criteria, review procedures, evaluation findings, and reference criteria for each subsection of a Safety Analysis Report. Development of BTP's and SRP's has only been possible because of experience with a large number of plants within the U.S. licensing process. In reality, these two sets of documents provide the detailed guidance for acceptability and licensability of nuclear systems and components.

Within FRG the body of experience has not been great enough to develop an analogous set of documents. Therefore, these detailed criteria are still determined as a result of review by TUV and GRS staff members (similar to the U.S. situation a decade ago).

With regard to nuclear standards, the development. efforts at ANSI are advanced to a considerably greater degree than those of DIN; through its KTA subsidiary. Table A-2 and Table A-3 are illustrative of the relative progress of these two organizations. ANSI standards are referenced in the Code of Federal Regulations, Regulatory Guides, and Standard Review Plans. In many cases, draft standards are also incorporated into criteria. The use of draft standards is not commonly employed in FRG. 
Several draft standards are under development with the ANS-53 committee for specific application to HTGR's. These standards attempt to address the unique system characteristics relating to helium coolant, PCRV, the prismatic graphite fuel system, et cetera. There is no information available which indicates that FRG organizations have undertaken a simflar program for HTR systems.

Additional guidance to FRG 1icensing has been reported in "Description of the Current Practice in Implementing the Safety Criteria for Nuclear Power Plants" and "Compilation of the Information Required for Examination Purposes in the Licensing Procedure of Nuclear Power Plants." These reports apparently contain a more detalled guide as to licensing criteria, but they are issued only in German and were not physically avallable for this review. 
TABLE A-1

USNRC BRANCH TECHNICAL POSITIONS

1.0 ACCIDENT ANALYSIS BRANCH (AAB)

No.

$\mathrm{AAB} \cdot 3-2$
Title

Tornado Design Classification

2.0 AUXILIARY AND POWER CONVERSION SYSTEMS BRANCH (APCSB)

No:

APCSB 3-1

APCSB 6-1

APCSB 9-1

APCSB 9-2

APCSB 9.5-1

APCSB $10-1$

\section{Title}

Protection Against Postulated Piping Failures in Fluid Systems Outside Containment

Design Criteria for Main Steam Isolation Valve Leakage-Control Systems for Direct Cycle BWR Plants

Overhead Handling Systems for Nuclear Power Plants

Residual Decay Energy for Light Water Reactors for Long-Term Cooling

Guidelines for Fire Protection for Nuclear Power Plants

Design Guidelines for Auxiliary Feedwater System Pump Drive and Power Supply Diversity for Pressurized Water Reactor Plants

\subsection{CORE PERFORMANCE BRANCH (CPB)}

No.

CPB $4.3-1$
Title

Westinghouse Constant Axial offset Contro1

\subsection{CONTAINMENT SYSTEMS BRANCH (CSB)}

No.

CSB $6-1$

$\operatorname{CSB} 6-2$
Title

Minimum Containment Pressure Model for PWR ECCS Performance Evaluation

Control of Combustible Gas. Concentrations in Containment Following a Loss-ofCoolant Accident 
CSB $6-3$

CSB $6-4$
Determination of Bypass Leakage Paths in Dual Containment Plants

Containment Purging During Normal Plant Operations

5.0 ELECTRICAL, INSTRUMENTATION AND CONTROL SYSTEMS BRANCH (EICSB)

No.

EICSB 1

EICSB 2

EICSB 3

EICSB 4

EICSB 5

$\operatorname{EICSB} 6$

EICSB 7

EICSB 8

EICSB 9

EICSB 10

EICSB 11

EICSB 12

EICSB 13

EICSB 14

EICSB 15

EICSB 16

EICSB 17

EICSB 18
Title

Backfitting of the Protection and Emergency Power Systems of Nuclear Reactors

Diesel-Generator Reliability Qualification Testing

Isolation of Low Pressure Systems From the High Pressure Reactor Coolant System

Requirements on Motor-Operated Valves in the ECCS Accumulator Lines

Scram Breaker Test Requirements--Technical Specifications

Capacity Test Requirements of Station Batteries--Technical Specifications

Shared Emergency. Electric Power Systems for Multi-Unit Generating Stations

Use of Diese1-Generator Sets for Peaking

Definition and Use of "Channel Calibration"-Technical Specifications

Electrical and Mechanical Equipment Seismic Qualification Program

Stability of Offsite Power Systems

Protection System Trip Point Changes for Operation with Reactor Coolant Pumps Out of Service

Design Criteria for Auxiliary Feedwater Systems

Spurious Withdrawals of Single Control Rods in Pressurized Water Reactors

Reactor Coolant Pump Breaker Qualification

Control Element Assembly (CEA) Interlocks in Combustion Engineering Reactors

Diesel-Generator Protective Trip Circuit Bypasses

Application of the Single Failure Criterion to Manually Controlled Electrically Operated Valves 
EICSB 19

EICSB 20

EICSB 21

EICSB 22

EICSB 23

EICSB 24

EICSB 25

EICSB 26

EICSB 27
Acceptability of Design Criteria for Hydrogen Mixing and Drywell Vacuum Relief Systems

Design of Instrumentation and Controls Provided to Accomplish Changeover from Injection to Recirculation Mode

Guidance for Application of Regulatory Guide 1.47

Guidance for Application of Regulatory Guide 1.22

Qualification of Safety-Related Display Instrumentation for Post-Accident Condition Monitoring and Safe Shutdown

Testing of Reactor Trip System and Engineered Safety Feature Actuation System Sensor Response Times

Guidance for the Interpretation of General Design Criterion 37 for Testing the Operability of the Emergency Core Cooling System as a. Whole

Requirements for Reactor Protection System Anticipatory Trips

Design Criteria for Thermal Overload Protection for Motors of Motor-Operated Valves

\subsection{EFFLUENT TREATMENT SYSTEMS BRANCH (ETSB)}

No.

ETSB $11-1$

ETSB 11-1 (Rev. 1)

ETSB $11-2$

ETSB $11-3$

ETSB $11-4$
Title

Design Guidance for Radioactive Waste Management Systems Installed in LightWater-Cooled Nuclear Reactor Power Plants

Design Guidance for Radioactive Waste Management Systems Installed in LightWater-Cooled Nuclear Reactor Power Plants

Design, Testing, and Maintenance Criteria for Normal Ventilation Exhaust System Air Filtration and Adsorption Units of L1ght-Water-Cooled Nuclear Power Reactor Plants

Design Guidance for Solid Radioactive Waste Management Systems Installed in Light-Water-Cooled Nuclear Power Reactor Plants

Seismic Design Classification and Quality Assurance Criteria for the Automatic Actuation of Safety Features

A-6 
7.0 MECHANICAL ENGINEERING BRANCH (MEB)

No.

MEB 3-1

MEB 2

MEB 5
Title

Postulated Break and Leakage Locations in Fluid System Piping Outside Containment

Pump and Valve Operability Assurance Program

Review Procedure for Prototype Systems and Components

8.0 MATERIALS ENGINEERING BRANCH (MTEB)

No.

MTEB 5-1

MTEB 5-2

MTEB 5-3

MTEB 5-5

MTEB 6-1

MTEB 10-1
Title

Interim Position on Regulatory Guide 1.31, Control of Stainless Steel Welding

Fracture Toughness Requirements

Monitoring of Secondary Side Water Chemistry in PWR Steam Generators

Fracture Toughness Requirements for ASME Code Class 2 and Class 3 Components

$\mathrm{PH}$ for Emergency Coolant Water

Turbine Disk Integrity

\subsection{REACTOR SYSTEMS BRANCH (RSB)}

No.

RSB 3-1

RSB 3-2

RSB 5-1

RSB 6-1
Title

Classification of Main Steam Components Other Than the Reactor Coolant Pressure Boundary for BWR Plants

Classification of BWR/6 Main Steam and Feedwater Components Other Than the Reactor Coolant Pressure Boundary

Design Requirements of the Residual Heat Removal System

Piping from the RWST (or BWST) and Containment Sumps to the Safety Injection Pumps

10.0 HYDROLOGY METEOROLOGY BRANCH (HMB)

$$
\text { No. }
$$

HMB
Title

Diffusion Conditions for Design Basis Accident Evaluation 


\section{Standards In Draft Form}

1. Reactor instrumentation and protection

2. Criticality safety

3. Reliability of nuclear installations

4. Containment vesse1s

5. Steel reactor pressure vessels

6. Concrete structures in nuclear power plants

7. Accessories for nuclear installations

8. Piping

9. Cleanliness requirements

10. Water decontamination

11. Ventilation and off-gas systems in nuclear installations

12. Emergency power supply

13. Recurrent inspections

14. Air locks

15. Hoists and lifts

16. Water basins for nuclear installations

17. Fuel element identification

18. Leak rate testing

19. Shutdown reactivity

20. Penetrations

21. Shutdown equipment

22. Pumps for nuclear installations

23. Nuclear auxiliary systems

24. Closure of containments 


\section{$\underline{\text { Standards Approved }}$}

1. Warning symbol for ionizing radiation

2. Nuclear engineering definitions

3. Remote control equipment for working behind shielding walls

4. Principles of criticality safety in processing and handling fissile materials

5. Safety aspects in designing thermal reactors regarding reactivity behavior

6. Requirements for accessible locks in nuclear power plants

7. Lead tile shielding walls against ionizing

8. Symbols for surface cleanliness of components at nuclear reactors

9. Classification according to elementary composition of concrete used for neutron shielding

10. Storage pools for fuel elements at nuclear reactors 
TABLE A-3

ANSI NUCLEAR STANDARDS UTILIZED IN REACTOR DESIGN

\begin{tabular}{|c|c|}
\hline $\mathrm{N} 1.1-1976$ & $\begin{array}{l}\text { Glossary of Terms in Nuclear Science \& Technology } \\
\text { (ANS-9) }\end{array}$ \\
\hline $\mathrm{N} 2.1-1969$ & Radiation Symbol (ISO 361) \\
\hline N2.3 - 1967 & $\begin{array}{l}\text { Immediate Evacuation Signal for Use in Industrial } \\
\text { Installations where Radiation Exposure May Occur }\end{array}$ \\
\hline N5.8- 1967 & Radioactive Waste Categories, Definition of \\
\hline N5.10 - 1968 & Classification of Sealed Radioactive Sources \\
\hline $\mathrm{N} 10.1-1968$ & Nuclear Reactor Classification System \\
\hline $\mathrm{N} 12.1-1971$ & Fissile Material Symbol \\
\hline $\mathrm{N} 13.1-19.69$ & $\begin{array}{l}\text { Guide to Sampling Airborne Radioactive Materials } \\
\text { in Nuclear Facilities }\end{array}$ \\
\hline N13.2 - 1969 & $\begin{array}{l}\text { Administrative Practices in Radiation Monitoring } \\
\text { (A Guide for Management) }\end{array}$ \\
\hline $\mathrm{N} 13.3-1969$ & Dosimetry for Criticality Accidents \\
\hline $\mathrm{N} 13.4-1971$ & $\begin{array}{l}\text { Portable X- or Gamma-Radiation Survey Instruments, } \\
\text { Speciflcation for }\end{array}$ \\
\hline $\mathrm{N} 13.5-1972$ & $\begin{array}{l}\text { Performance Specifications for Direct Reading } \\
\text { and Indirect Reading Pocket Dosimeters for } \\
X \text { - and Gamma-Radiation }\end{array}$ \\
\hline $\begin{array}{l}\text { N13.6-1966 } \\
\quad(\mathrm{R} 1972)\end{array}$ & $\begin{array}{l}\text { Practice for Occupational Radiation Exposure Records } \\
\text { Systems }\end{array}$ \\
\hline $\mathrm{N} 13.7-1972$ & Criteria for Film Badge Performance \\
\hline N13.10 - 1974 & $\begin{array}{l}\text { Specification and Performance of On-Site Instrumentation } \\
\text { for Continuously Monitoring Radioactivity in Effluents }\end{array}$ \\
\hline N14.9.1 - 1976 & $\begin{array}{l}\text { Packaging for Transportation of Liquid Radioactive } \\
\text { Aqueous Waste from Nuclear Power Plants }\end{array}$ \\
\hline N14.10.2 - 1973 & $\begin{array}{l}\text { Administrative Guide for Obtaining Department } \\
\text { of Transportation Special Permits for Radio- } \\
\text { active Materials Shipments }\end{array}$ \\
\hline N14.10.3 - 1975 & $\begin{array}{l}\text { Administrative Guide for Verlfying Compliance with } \\
\text { Packaging Requirements for Shipments of Radioactive } \\
\text { Material }\end{array}$ \\
\hline
\end{tabular}




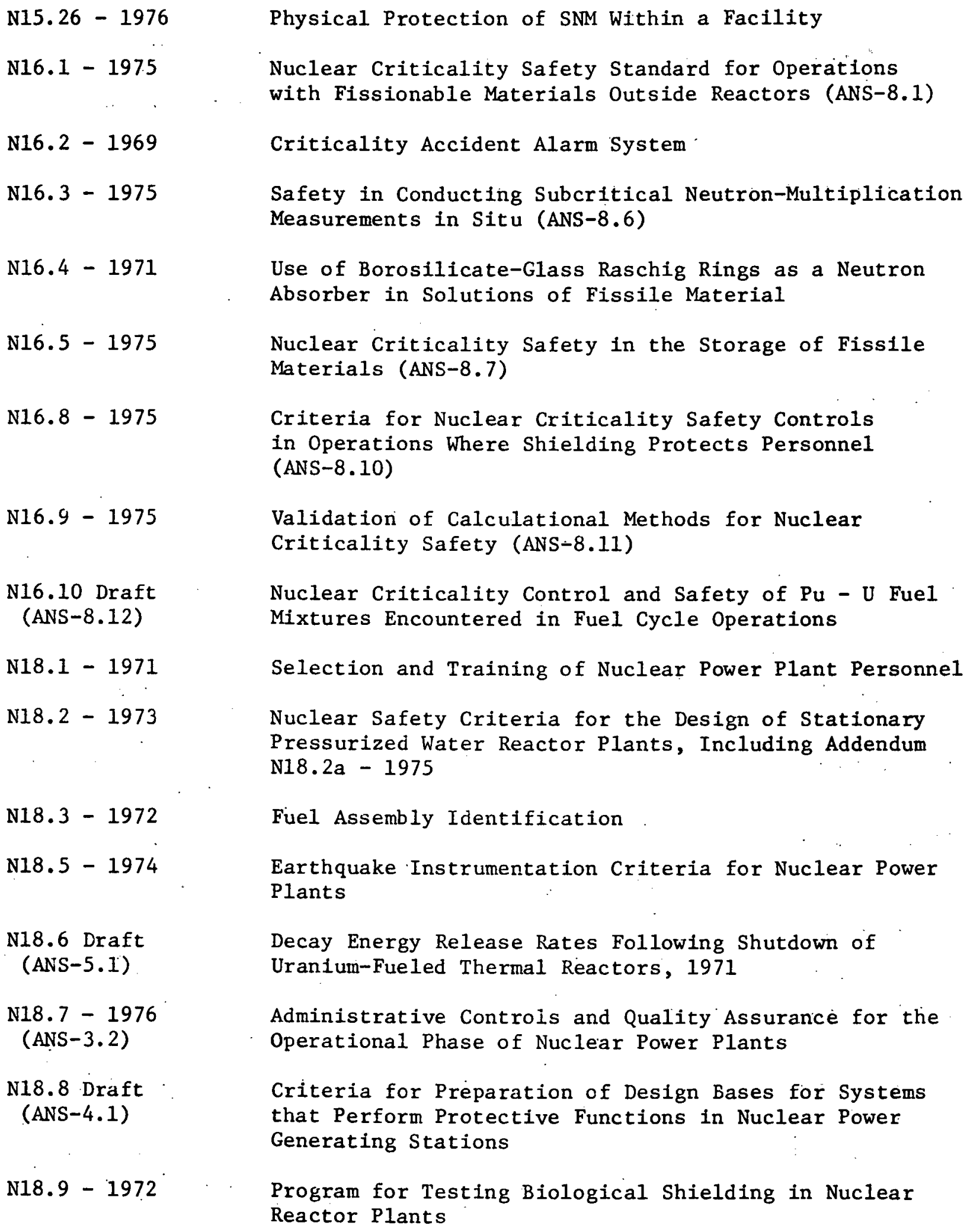




\section{TABLE A-3 (Continued)}

N18.10 Draft

(ANS-59.4)

N18.17 - 1973

N41. 2

N41. 3

N41.4 - 1976

N41.6 Draft

N41.10 - 1975

N41.12 - 1975

N41.14 Draft

N41.15 - 1976

N41.17 Draft

N41.21 Draft

N41.24 - 1976

N41. $28-1976$

N42.1 - 1969

(R 1974)
Fire Protection Criteria for Safety-Related Structures and Equipment for Water-Cooled and Moderated Nuclear Power Generating Plants - issued for trial use and comment, 1975

Industrial Security for Nuclear Plants

Trial-Use Guide for the Application of the Single-Failure Criterion to Nuclear Power Generating Station Protection Systems (IEEE Std. 379-1972)

Criteria for Periodic Testing of Class IE Power and Protection Systems

Guide for General Principles of Reliability Analysis of Nuclear Power Generating Station Protection Systems (IEEE Std. 352-1975)

Trial-Use Guide for Type Test of Class I Electric Valve Operators for Nuclear Power Generating Stations (IEEE Std. 382-1975)

IEEE Std. for Type Test of Class IE Electric Cables, Field Splices and Connections for Nuclear Power. Generating Stations (IEEE Std. 383-1974)

Criteria for Class IE Power Systems for Nuclear Power Generating Stations (IEEE Std. 308-1974)

Trial-Use Standard, Criteria for Separation of Class IE Equipment and Circuits (IEEE Std. 384-1974)

Practice for Maintenance Testing and Replacement of Large Lead Storage Batteries for Generating Stations and Substations (IEEE Std. 450-1975)

IEEE Trial-Use Guide for Class III Control Switchboards for Nuclear Power Generating Stations (IEEE Std. 420-1973)

Instrument Systems for Leak Detection, 19.75

(ISA SP67.3)

Design and Installation of Large Lead Storage Batteries for Power Plants (IEEE 484-75)

IEEE Standard Method for Identification of Documents Related to Class IE Equipment and Systems for Nuclear Power Generating Stations (IEEE Std. 494-1974)

Test Procedure for Semiconductor Radiation Detectors (for Ionizing Radiation) (IEEE Std. 300-1969) 
N42.2 - 1976

N42.3 - 1969

(R 1974)

N42.4 - 1971

N42.5 - 1965

(R 1971)

N42.6 - 1964

(R 1971)

N42.7 - 1972

N42.8 - 1972

N42.9 - 1972

N43.2 - 1971

N45. $2-1971$

N45.2.1 - 1973

$\mathrm{N} 45.2 .2-1972$

N45.2.3 - 1973

$N 45.2 .4-1972$

$N 45.2 .5-1974$
Test Procedure for Amplifiers and Pre-Amplifiers for Semi-Conductor Radiation Detectors (for Ionizing Radiation) (IEEE Std. 301-19.76.)

Standard Test Procedures for Geiger-Muller Counters (IEEE Std. 309-1970)

High Voltage Connectors for Nuclear Instruments

Bases for GM Counter Tubes

Interrelationship of Quartz-Fiber Electrometer-Type Dosimeters and Companion Dosimeter Chargers

Criteria for Protection Systems for Nuclear Power Generating Stations (IEEE Std. 279-1971)

Test Procedures for Germanium Gamma-Ray Detectors (IEEE Std. 325-1971)

Standard Test Procedures for Photomultipliers for Scintillation Counting and Glossary for Scintillation Counting Field (IEEE Std. 398-1972)

Radiation Safety for X-Ray Diffraction and Fluorescence Analysis Equipment (NBS Handbook III)

Quality Assurance Program Requirements for Nuclear Power Plants

Cleaning of Fluid Systems and Associated Components During Construction Phase of Nuclear Power Plants

Packaging, Shipping, Receiving, Storage and Handling of Items for Nuclear Power Plants (During the Construction Phase)

Housekeeping During the Construction Phase of Nuclear Power Plants.

Installation, Inspection, and Testing Requirements for Instrumentation and Electric Equipment During the Construction of Nuclear Power Generating Stations (IEEE Std. 336-1971)

Supplementary Quality Assurance Requirements for Installation, Inspection, and Testing of Structural Concrete and Structural Steel During the Construction Phase of Nuclear Power Plants 


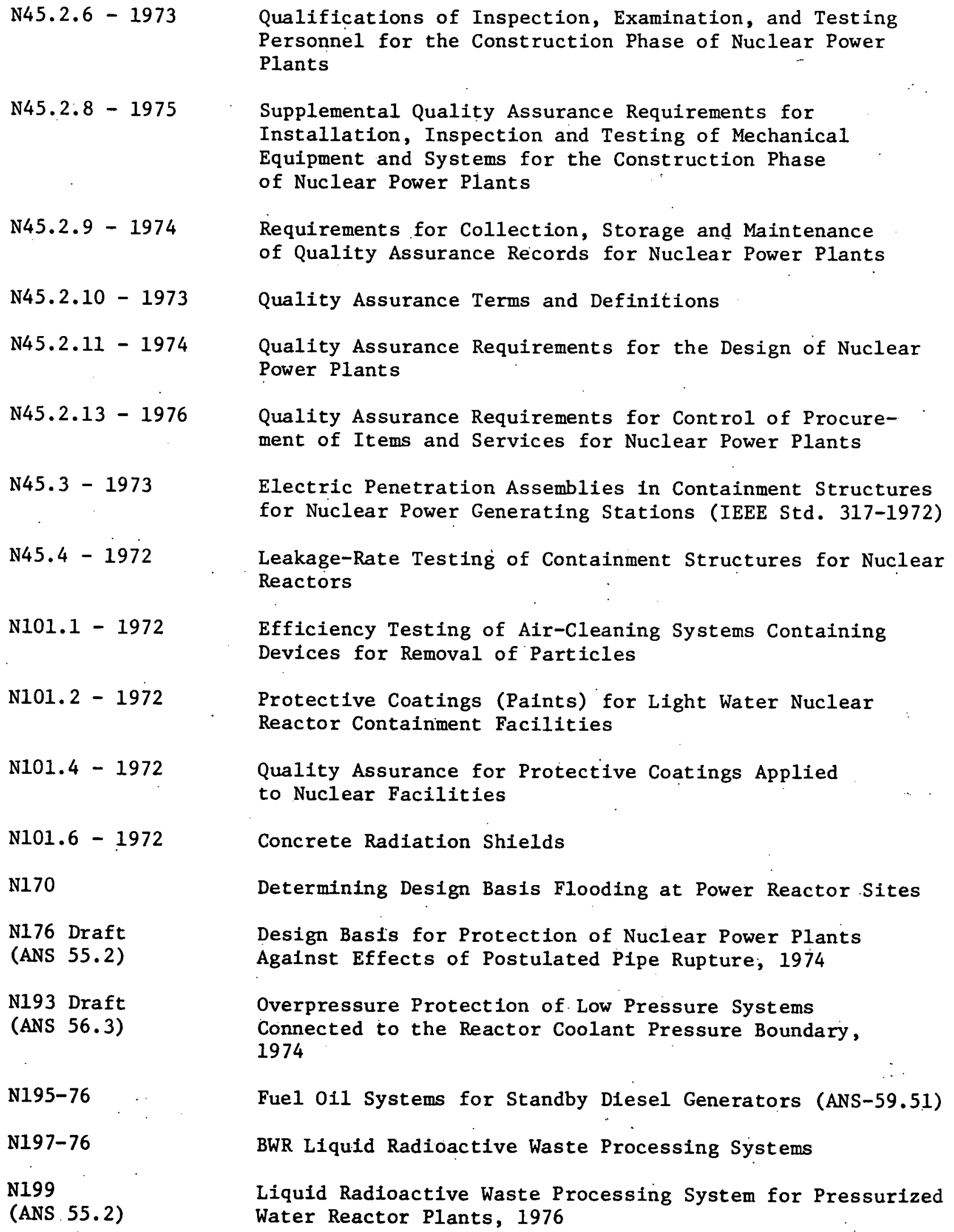

Qualifications of Inspection, Examination, and Testing Personnel for the Construction Phase of Nuclear Power Plants

Supplemental Quality Assurance Requirements for Installation, Inspection and Testing of Mechanical Equipment and Systems for the Construction Phase of Nuclear Power Plants

Requirements for Collection, Storage and Maintenance of Quality Assurance Records for Nuclear Power Plants

Quality Assurance Terms and Definitions

Quality Assurance Requirements for the Design of Nuclear Power Plants

Quality Assurance Requirements for Control of Procurement of Items and Services for Nuclear Power Plants

Electric Penetration Assemblies in Containment Structures for Nuclear Power Generating Stations (IEEE Std. 317-1972)

Leakage-Rate Testing of Containment Structures for Nuclear Reactors

Efficiency Testing of Air-Cleaning Systems Containing Devices for Removal of Particles

Protective Coatings (Paints) for Light Water Nuclear Reactor Containment Facilities

Quality Assurance for Protective Coatings Applied to Nuclear Facilities

Concrete Radiation Shields

Determining Design Basis Flooding at Power Reactor Sites

Design Basis for Protection of Nuclear Power Plants Against Effects of Postulated Pipe Rupture; 1974

Overpressure Protection of. Low Pressure Systems Connected to the Reactor Coolant Pressure Boundary, 1974

Fuel 0il Systems for Standby Diesel Generators (ANS-59.51)

BWR Liquid Radioactive Waste Processing Systems

Liquid Radioactive Waste Processing System for Pressurized Water Reactor Plants, 1976 
N200 Draft

(ANS 55.4)

N210 - 1976

(ANS 57.2)

N212 Draft

(ANS 52.1)

N213 Draft

(ANS 23.1)

N237 - 1976

N265 - 1974

N271

(ANS 56.2)

N275 Draft

(ANS 56.1)

N278.1 - 1975

N319

N412 - 1975

$N 413-1974$

N510 - 1975

N512 - 1974

N524 - 1976

(ANS N18-29)

N543 - 1974

N546 - 1976

(ANS 3.4)

N559 - 1974
Design Criteria for Gaseous Radioactive Waste Processing. System for PWRs, Sept. 1975

Design Objectives for Light Water Reactor Spent Fuel Activities, 1976

Nuclear Safety Criteria for the Design of Stationary Boiling Water Reactor Plants, May 1974

Nuclear Safety Criteria for the Design of Stationary Gas-Cooled Reactor Plants, Jan. 1974

Source Term Specification, 1976 (ANS-18.1)

Specification for Special Requirements for Bolting Material for Nuclear and Other Special Applications (ASTM A614-73)

Containment Isolation Provisions for Fluid Systems, 1976

Design Basis for Hydrogen Treatment in Containment, 1975

Functional Specification for Self-Operated and PowerOperated Safety-Related Valves

Personnel Neutron Dosimeters (Energies Less Than $20 \mathrm{MEV}$ )

Determination of Nuclear Reactor Rates Distributions and Reactivity of Clear Reactors

Guidelines for the Documentation of Digital Computer Programs

Testing of Nuclear Air-Cleaning Systems

Protective Coatings (Paints) for the Nuclear Industry (Revision \& Redesignation of N5.9 - 1967)

Nuclear Plant Reliability Data Collection and Reporting

General Safety Standards for Installations Using NonMedical X-Ray and Sealed Gamma-Ray Sources

Medical Certification and Monitoring of Licensed Nuclear Power Plant Operators

Speclal Requirements for Steel Plates for Nuclear and other Applications (ASTM A647-73) 
TABLE A-3 (Continued)

N561 - 1974

N564 - 1974

N658 Draft

(ANS 51.7)

N626.1 - 1975

N626.2 - 1976

(ACI-359.74)

N661 Draft

N677 Draft

(ISA SP67.2)

N678 Draft

(ISA SP67.1)

N693
Special Requirements for Forgings and Bars for Nuclear and Other Special Applications, Specification for (ASTM A654-73)

Special Requirements for Pipe and Tubing for Nuclear and Other Special Applications, Specifications for (ASTM A655-73)

Single-Fallure Criteria for PWR Fluid Systems, May 1975

Qualifications and Duties for Authorized Nuclear Inservice Inspectors

Qualiffcations and Duties for Authorized Nuclear Inspection (Concrete)

Evaluation of Anticipated:Transients Without Trip on Pressurized Water Reactor Plants (Issued for Trial Use and Comment), Mar. 1975

Instrument Piping and Tubing (Impulse Lines) for Nuclear Power Plants, 197.5

Online and offline Transducer and Transmitter Installations of Safety Classifications 1, 2, and 3,1975

Fire Protection Practice for Facilities Handling Radioactive Material 


\section{A.3 SPECIFIC DIFFERENCES IN CRITERIA}

A comprehensive determination of specific differences is difficult since, a1though FRG criteria were developed later than and with cognizance of U.S. criteria (in most instances), they were developed along completely independent lines. Therefore, individual formats are different for corresponding U.S. and FRG regulations. The following is an attempt to describe specific differences in criteria for areas of safety significance. It is most 1ikely not comprehensive but, rather, indicative of differences which must be resolved.

\section{A.3.1 FRG SAFETY CRITERIA}

- Criteria 2.1, Quality Assurance and Criteria 2.2, Testability These are simflar In scope to U.S. General Design Criteria 1 (GDC 1) and 10CFR50 Appendix B; however, the definition and intent of QA appears to be slightly different in the FRG. Within the U.S., the intent of QA follows the classical definition in that it assures of more detailed documentation and traceability of what has been done for systems which are most critical to safety. FRG regulations state that "the quality of each plant component ... shall be in accordance with its safety-related significance. To this end, such principles and procedures shall be applied...."; and "approved standards of technology must be reviewed." Therefore, within the FRG the function of QA is to ensure a level of quality rather than just to ensure the documentation of whatever level of quality is requested. This difference is manifested in greater emphasis on inplant inspection of construction and fabrication procedures rather than on records keeping and traceability (as in the U.S.).

- Criteria 2.3, Radiation Exposure of the Environment These are analogous to 10CFR50 Append1x $A$ in that both regulations set forth radiological release limits for normal operation and therefore determine the design basis for radwaste management systems. The fundamental difference occurs in the values specified:

FRG

$$
\begin{aligned}
& \text { liquid release }-30 \text { mrem } \\
& \text { gaseous release }-30 \text { mrem }
\end{aligned}
$$


Infant thyrold

from food chain - 90 mrem

U.S.

$$
\begin{aligned}
\text { liquid release } & -3 \text { mrem whole body } \\
& -10 \text { mrem any organ } \\
\text { gaseous release } & -10 \mathrm{mrad} \text { gamma radiation } \\
& -20 \mathrm{mrad} \text { beta radiation }
\end{aligned}
$$

total iodine and

radioactive particulate - 5 mrem whole body

$$
\text { - } 15 \text { mrem skin }
$$

The FRG values and approach represent a set of dose limits (e.g., design basis fence line cow) which has now been replaced within U.S. criteria by more general and reduced dose values and by an ALARA approach: This approach requires a cost-benefit analysis to demonstrate that values are As Low As Reasonably Achievable, below specified limits. A value of $\$ 1000 / \mathrm{man}-\mathrm{rem}$ is used for this evaluation. The net result is that, within the U.S., plants cannot realistically expect to come close to stated dose limits. The specific approach to applying Criteria 2.3 in the FRG is not known. RSK Guideline 2.3.1 does not address approaches except to say that a radioecological study must be performed to demonstrate that releases are as low as possible.

- Criteria 2.4, Plant Radiation Hazáard

This regulation addresses occupational exposure and is analogous to 10CFR20. The FRG Design Criteria and RSK Guidelines do not give a specific dose limit; however, the Radiation Protection Ordinance was recently. changed to specify:

$\underline{\text { FRG }}$

maximum annual

individual dose - 5 rem

The U.S. specifies personnel exposure 1imits in 10CRF20 as: 
U.S.

maximum quarter1y

individual dose $\quad-3 \mathrm{rem}$

maximum annual

individual dose $\quad-5(\mathrm{~N}-18)$ rem, where $\mathrm{N}$ equals age of worker

Both U.S. and FRG criteria specify an ALARA approach for occupational exposure-related design. However, FRG criteria carry this one step further by speclfying that "facility components:be specifically designed and installed for ease of maintenance and repair." This latter aspect has been of increasing concern within the U.S., where plant total occupational exposures are rising rap- . idly, but it has not been incorporated in specific criteria.

- Criteria 2.5, Arrangement of the Work Area, Work Cycle, Work Environment

There are no equivalent U.S. eriteria which stipulate working conditions optimal to safety. Within the U.S. this consideration is usually reserved for OSHA regulatory enforcement under the Department of Labor and is also a labor union concern.

- Criteria 2.6, Effects from External Events

These are comprehensive criteria. which address the effects from both man-made and natural phenomena external to the plant. As such, they cover a broad range of U.S. criteria including GDC 2 and 4, 10CFR100 Appendix A, Reg. Guides 1.59 (Revision 1), 1.60, 1.61 (Revision 1), 1.78, 1.91, 1.95 (Revision 1), 1.102 (Revision 1), and 1.117 .

Regarding seismic design, there are no specific numerical guidelines given in the Criteria, and RSK Guidelines in this area do not address natural phenomena. However, it has been reported that within FRG three levels of earthquake intensity are considered (Ref, A1) :

1. Basic earthquake intensity $\left(l_{1}\right)$ - immediate plant vicinity and probability greater than $10^{-2} / \mathrm{yr}$. 
2. Extended earthquake activity $\left(l_{2}-50 \mathrm{~km}\right.$ vicinity of plant and probability between $10^{-2}$ and $10^{-3} / \mathrm{yr}$.

3. Maximum intensity of earthquake $\left(l_{3}\right)$ - maximum feasible according to scientific knowledge with probability less than $10^{-3} / \mathrm{yr}$.

FRG points ont that their criteria are comparable to the USA except SSE $10^{-5}$ year instead "f $10^{\prime \prime} /$ year.
If this procedure is correct, it represents a significant departure from U.S. practices which, while not specifically documented in the criteria, are based on a geological survey in accordance with 10CFR100 Appendix A and Regulatory Guides 1.60 and 1.61, leading to a single maximum $\mathrm{OBE}$ and SSE earthquake determined on an approxmate probability basis of one per reactor lifetime and $10^{-6} / \mathrm{yr}$, respectively.

With regard to human-related offsite hazards (chemical explosion, toxic vapor, aircraft impact, etc.) there is a significant deviation between U.S. and FRG criteria. Within the U.S., a procedure has been established to determine which offsite hazards present a credible threat to be considered as design basis events. As defined in Standard Review Plan 2.2.3, this basis is that the probability of occurrence for a single event should not exceed a value of $10^{-7} / \mathrm{yr}$ when calculated on a realistic basis or $10^{-6} / \mathrm{yr}$ on a conservative basis. Standard Review Plan 3.5.1.6 presents a similar criterion specifically for aircraft impact. Therefore, if the applicant can demonstrate that an event is not credible, it does not have to be accounted for within the design. For aircraft impact (crashes) and for other offsite hazards, most applicants have been able to demonstrate that these events do not constitute a design basis accident. Therefore, fewer U.S.-designed containments are "burst proof.".

Criteria 2.6 states that "... the most damaging natural influence or other external influence must be considered ...." Therefore, for FRG plants, all such offsite hazards must be considered within the design basis. The FRG approach is based on an overall assessment of aircraft hazards, etc., for the country, with the recognition that probabilities will be relatively uniform at all 
sites. The:U.S. approach recognizes a potential diversity in natural and offsite hazards in various regions of the country, allowing the applicant to evaluate the credibility of events on a case-by-case basis.

\section{- Criteria 2.7, Fire Protection and Explosion}

KTA comments thut the FRG criteria are comparable to those of the USA; see KTA Rule. VB210)i (prolimimary repert).
These criteria are similar to GDC 3. Their interpretation in RSK Guideline 2.8, however, is not nearly so comprehensive as Standard Review P1an 9.5.1, issued after the Browns Ferry Fire. This SRP calls for a fire design strategy, allocating plant facilities into fire zones, and requires consideration of fire protection as a fundamental concern during design review of new plant construction. Therefore, additional emphasis is placed on meeting fire-protection requirements within the U.S. criteria.

- Criteria 2.8, Access Control and Areas to Be Restricted

These criteria pertain to physical security and are analogous to requirements in the recently revised 10CFR73. No specific guidance is given in RSK Guidelines; however, it is reported (Al) that the approach is to protect the reactor building to limit violent entry and to ensure spatial redundancy of safety systems. U.S. revised criteria call for emphasis on both perimeter monitoring and reactor building access, plus the separation of a facility into vital areas wherein individual access is controlled. Therefore, while the overall intent appears to be consistent, the influence of security procedures on plant design may differ from U.S. to FRG criteria.

- Criteria 2.9, Emergency Exits and Means of Communication

- These appear to be similar in nature and content to 10CFR50 Appendix E and 10CFRI00 requirements except that U.S. criteria call for the issuance of a separate Emergency Plan, while this is not explicitly called for in FRG criteria.

- Criteria 2.10, Decommissioning of Nuclear Power Plants

These have no analogy in U.S. licensing requirements. Regulatory Guide 1.86 addresses requirements, but these are not necessary at the time of initial licensing. 
- Criteria 3.1, Reactor Design and 3.2, Inherent Safety

These are similar to GDC 10 and 11 . However, the interpretation of these criteria through RSK guidelines creates a noticeable difference in design requirements.

FRG guidelines call for two independent shutdown systems which are diverse, independent, and capable of maintaining cold subcritical conditions. This requirement has been suggested by NRC through its industry discussions on ATWS. At present, however, no operating plants in the U.S. meet these criteria and none have committed themselves to meeting it. in the future.

Additional items such as a one percent reactivity margin with the worst rod stuck-out, rod ejection accommodation, loose parts monitoring, and pressure vessel internal vibration qualification are similar to U.S. regulatory requirements. However, RSK Guidelines are very brief in their mention of these items, and it is not possible to ascertain if detailed implementation is consistent with U.S. practices.

- Criteria 4.1, Reactor Coolant Pressure Boundary

These criteria, pertaining to $\mathrm{RCPB}$ performance, are similar to $\operatorname{GDC} 30,31$, and 32 . The interpretation of spectfic requirements through RSK Guidelines is in general similar to that given in 10CFR50 Appendix $G$ although there are specific differences in testing procedures which are beyond the scope of this comparison (e.g., temperature requirements for pressure tests).

- Criteria 4.3, Residual Heat Removal After LOCA

These criterla have no specific bearing for HTR systems. A suggestion to revise GDC 35 has been made to accommodate HTGR systems, but has not been implemented. No analogous FRG criteria for PBR's has been reported.

RSK Guideline discussions (4.3.1 - 15 and 16) of hydrogen generation recommend that concentrations be controlled by recombining and that "purging of the containment should be avoided if 
It is further reported that this criteria may require an ultimate heat sink with two water sources: one to withstand natural phenomena and the other for human-related incidents (e.g., aircraft impact). (A1)

The specific interpretation of these criteria is not discussed in RSK Guidelines. U.S. criteria limit considerations to a single failure criteria, except in unusual circumstances (e.g., a long run of piping) when passive failures must be considered in addition to active failures. U.S. ultimate heat sink design as defined in GDC 44 must be seismically qualified but is not required to meet the redundancy of supply mentioned above.

- Criteria 7.1, Emergency Power Supply

The requirements of these criteria, as amplified by RSK Guideline 7, call for an electrical supply which is both physically and electrically separate. This entails not only two physically independent connections but also a separate bus arrangement, diverse voltage levels on incoming lines, and N-2 failure criteria for diesel generators (i.e., either $3 \times 100 \%$ capacity or $4 \times 50 \%$ diesel generator sets). U.S. criteria, as discussed in GDC 17, require only physically separate incoming lines, going through a common bus, with an intertie of both lines to two diesel generator sets (meeting the single-failure criterion).

- Criteria 8.1 , Containment of the Reactor

These criteria discuss safety analysis, performance criteria, and leak rate testings. These points are amplified by corresponding RSK Guidelines. These criterla are generally consistent with U.S. criteria contained in GDC 50 thru 57, 10CFR50 Appendix J, and Regulatory Guides 1.7, 1.11, 1.15 (Revision 1), 1.18 (Revision 1), 1.19 (Revision 1), 1.55, 1.57. However, the guidelines for containment pressure analysis differ as follows:

FRG

total pressure

- maximum design basis accident, plus one total steam generator inventory, plus fifteen percent. 
possible." This is not consistent with Regulatory Guide 1.7, which allows for controlled purging (especially for PWR's) as a viable : design option.

RSK Guideline 4.3.2.1 calls for an ATWS analysis but leaves open the possibility for mitigation of consequences.

- Criteria 5.3, Equipment for Control and Shutdown of the Reactor This is analogous to GDC 20 through 25. RSK Guidelines present an additional requirement that, assuming a faflure of all control room functions, it must be possible to shut down the reactor and maintain residual cooling. This is further interpreted to mean that a separate emergency control station is required. U.S. criteria, based primarily on Standard Review Plan 7.4 considerations, require the capability of remote shutdown; however, this does not have to be from a central control panel or via automatic actuation, much less from an explicit alternate control station.

\section{- Criteria 6.1, Reactor Protection System}

These criteria set forth the basis for what is known as the (N-2) failure criterion. It states that "... at least two criteria for initiation of protective actions shall be avallable..."; and "as far as possible, different physical variables shall be used as initiating criteria."

Based on these criteria, both an active and passive failure must be considered in separate loops for the Emergency Cooling system. (A2) With the consideration that one active loop may be idle for testing, this requires four active loops. It has been additionally reported that this criteria implies the following:

Minimum Configuration - 4 safety circuits of $50 \%$ capacity without diversity of supply.

Desirable Configuration - 3 safety circuits of $100 \%$ capacity with diversity of supply for long-term operation. 
subcompartment pressure - maximum design basis accident, plus fifteen percent

U.S.
total pressure
- maximum design basis accident, p].us ten percent
subcompartment pressure
- maximum design basis accident, plus forty percent

- Criteria 9.1, Ventilation Facilities

These criteria and corresponding RSK Guidelines present performance criteria which are in general consistent with U.S. practices; however, neither mentions ALARA design objectives for these systems or use of HEPA filters (or equivalent) and associated performance objectives.

- Criteria 11.1, Manipulation and Storage of Nuclear Fuels and Other Radioactive Materials

These criteria are analogous to GDC 61 in that they address spent fuel, and to GDC 60 for radwaste. RSK Guidelines are significantly lacking in detail for this area (e.g., discussion of seismic qualification and quality of radwaste storage equipment, ALARA design considerations of equipment, performance criteria, etc.). Discussions of spent fuel storage do not discuss criticality requirements or fuel handling accidents such as those addressed in GDC 26 and Standard Review Plan 9.2.

It has been reported ${ }^{(3)}$ that provisions of the FRG Waste Disposal Act require applicants to surrender these wastes for disposal (and subject them to fines if they don't). These requirements are in contrast to U.S. procedures requiring applicants to dispose of low-level wastes themselves and to store any high-level waste for ultimate government disposal. This disparity in criteria may create incompatibilities in FRG waste treatment systems as opposed to U.S. requirements. 


\section{A.4 ADDITIONAL U.S. REQUIREMENTS}

Aside from specific differences between FRG criteria and their equivalent U.S. counterparts, there are additional U.S. requirements not covered by FRG criteria. These requirements include:

\section{- Combined Loadings for Category I Fluid Systems}

GDC 2 and Regulatory Guide 1.48 set forth the requirements for specifying loadings as the design basis for these systems. These requirements include the combination of loadings from seismic events with LOCA loadings in determination of the consequences from design basis accidents. This requirement is explicitly deleted from FRG criteria, where the position has been established that, due to the inherent NSSS design against SSE forces, it will not be possible to have a seismically induced LOCA. Therefore, within the FRG abnormal loadings are limited to LOCA force considerations. This position has probably developed due to the low seismic activity in most areas of Western Europe; however, it would not be consistent with the seismological conditions in many areas of the U.S.

- High-Energy Pipe Whip

GDC 4 and Regulatory Guide 1.46 require an analysis of the effect of pipe whip for high-energy lines inside the containment. The applicant must verify that such lines cannot damage equipment vital to safety. This requirement has informally been extended

HRB indicates that in principle. the German re. quirements are the same as in the USA. to lines outside of containment. The FRG has no equivalent analysis requirement, possibly because of their specification of physical separation for all trains of safety-related equipment. This feature of physical separation is one method whereby U.S. plants can meet the pipe whip criterion; however, within the U.S., it is also possible to meet it by utilization of suitable barriers and restraints.

- Fuel Storage Pool Overhead Crane \& Cask Systems

GDC 61, as Interpreted by Branch Technical Position APCSB 9.1 and Regulatory Guide 1.13, requires a comprehensive evaluation of potential accidents from spent fuel shipping cask drop or 
tipping into the storage pool. Requirements for safety redundancy in overhead handling cranes are also given. No such equivalent FRG criteria are given, indicative of less emphasis on fuel handling and storage systems given in these criteria.

- Offsite Accidental Dose Release

Within the U.S., criteria 10CFR100 specify accidental radiological dose limits which are distinct and separate from normal release limits given in 10CFR50 Appendix $I$. Within the FRG these limits appear in the revised Radiation Protection Ordinance. Criteria for these offsite accident dose limits are as follows:

FRG

two-hour site boundary dose - 5 rem whole body.

$$
\text { - } 15 \text { rem thyroid }
$$

U.S.

$$
\begin{aligned}
& \text { two-hour site boundary dose }-\quad 25 \text { rem whole body } \\
& -300 \text { rem thyroid } \\
& \begin{aligned}
\text { total low population zone dose } & -25 \text { rem whole body } \\
& -300 \text { rem thyroid. }
\end{aligned}
\end{aligned}
$$

HRB cites KTA rule *3801 as reference for similar considerations in the FRG.
A range of accidents must be considered with varying degrees of probability for occurrence, and the percentage of these dose limits acceptable for each accident varies with these probabilities. FRG accident analysis appears to be based on a single worst-case design basis event, with the dose constraints lower than those of the U.S. 


\section{A. 5 REFERENCES}

(AI) Richardson, J.A., "Summary Comparison of West European and U.S. Licensing Regulations for LWR's," Nuclear Engineering International, February 1976.

(A2) Baranowski, H.K., "Safety Criteria for the Adoption of the B\&W Concept to the Mulheim-Kulich NPD," Babcock-Brown Boveri Reactor GmbH. 